\title{
GTP-17-1386
}

\section{HEAT TRANSFER IN THE CORE COMPRESSOR UNDER ICE CRYSTAL ICING CONDITIONS}

\author{
Alexander Bucknell \\ University of Oxford, Oxford, UK \\ alexander.bucknell@eng.ox.ac.uk \\ Geoff Jones \\ Rolls-Royce Plc, Derby, UK
}

\author{
Matthew McGilvray \\ University of Oxford, Oxford, UK
}

Alasdair Reed

Rolls-Royce Plc, Derby, UK

\author{
David R. H. Gillespie \\ University of Oxford, Oxford, UK \\ David R. Buttsworth \\ University of Southern Queensland \\ Toowoomba, AU
}

\begin{abstract}
It has been recognised in recent years that high altitude atmospheric ice crystals pose a threat to aircraft engines. Instances of damage, surge and shutdown have been recorded at altitudes significantly greater than those associated with supercooled water icing. It is believed that solid ice particles can accrete inside the core compressor, although the exact mechanism by which this occurs remains poorly understood.

Development of analytical and empirical models of the ice crystal icing phenomenon is necessary for both future engine design and this-generation engine certification. A comprehensive model will require the integration of a number of aerodynamic, thermodynamic and mechanical components. This paper studies one such component, specifically the thermodynamic and mechanical processes experienced by ice particles impinging on a warm surface.

Results are presented from an experimental campaign using a heated and instrumented flat plate. The plate was installed in the Altitude Icing Wind Tunnel (AIWT) at the National Research Council of Canada (NRC). This facility is capable of replicating ice crystal conditions at altitudes up to 9 $\mathrm{km}$ and Mach numbers up to 0.55 [1]. The heated plate is designed to measure the heat flux from a surface at temperatures representative of the early core compressor, under varying convective and icing heat loads.

Heat transfer enhancement was observed to rise approximately linearly with both total water content and particle diameter over the ranges tested. A Stokes number greater than unity proved to be a useful parameter in determining whether heat transfer enhancement would occur. A particle energy parameter was used to estimate the likelihood of fragmentation. Results showed that when particles were both ballistic and likely to fragment, heat transfer enhancement was independent of both Mach and Reynolds numbers over the ranges tested.
\end{abstract}

\section{INTRODUCTION}

Over 240 icing related engine events have been recorded since 1990. Mason et al. [2] analysed 46 of these events, many of which occurred at altitudes above $7000 \mathrm{~m}$, the recognised upper limit at which water can exist in liquid form.

Fig. 1 shows the fan and compressor of a generalised two shaft turbofan engine, with the low pressure compressor (LPC) stators and intercompressor duct highlighted as areas of potential ice crystal accretion. Mason et al. theorised that partially melted ice particles may stick and refreeze on these surfaces, thus the heat transfer rate between particles and the surface are of great interest.

Fundamental experimental studies have been performed in recent years to further physical understanding and thus enable modelling capability. A key observation is that ice crystal accretion cannot initiate without liquid water present at the accretion location. A study was conducted by the NRC, Boeing and NASA Glenn Icing Research Branch in 2009 [3] using an S-shaped intercompressor duct with integral titanium strut. The study concluded that the likelihood of accretion is maximised over a specific range of liquid-to-total water content ratios ('melt ratios'). At ratios below this range, particles are more likely to bounce, whereas at high ratios the low ice quantity and water runback also inhibit accretion. Surface thermocouples

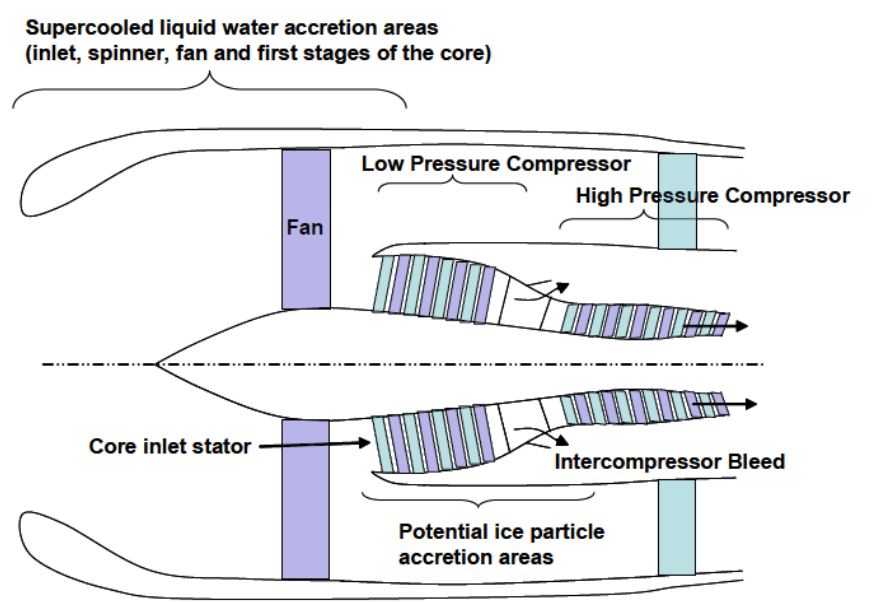

Fig. 1 - Schematic of two shaft turbofan, with potential ice accretion sites highlighted [2] 
were able to indicate the onset of accretion, however could not detect shedding and re-forming events. A wedge-shaped simplified aerofoil was used by NASA/NRC in the Research Altitude Test Facility (RATFac) in 2010 [4] to measure accretion growth rates for a range of aerodynamic and icing conditions, and also to measure heat transfer in dry conditions.

Further research at RATFac by Currie et al. [5] using simple axisymmetric geometries led to a proposed optimal melt ratio band of 10-17\%. The data from this study is shown in Fig. 2. These findings imply that during previous engine events in ice crystal conditions, a proportion of liquid water within this critical band was present at the point of accretion. Currie et al. [6] previously reported on experiments to develop altitude scaling rules for mixed phase accretion. As part of these studies, they determined that the accretion growth rate and steady state volume were insensitive to how the desired melt ratio was generated - whether by natural melt of ice particles or by injection of supplemental liquid water.

However, what remains unclear in the engine environment is what proportion of the liquid water at the point of accretion is generated by particle-air heat transfer, and what proportion by particle-surface heat transfer. Of these, particlesurface heat transfer is significantly more difficult to predict analytically as it depends strongly on the dynamics of the particle -surface impact.

Roisman et al. [7] conducted experiments on single particle impacts, using spherical ice particles. These were used to develop analytical and semi-empirical models for particle impact with dry, wet and heated surfaces. However, the models are unable to capture particle-particle interactions, and neglect the effect of bulk particle melting on the convective heat transfer from the surface.

Therefore at present there is an absence of data in the open literature on surface heat transfer enhancement in bulk mixed phase or glaciated conditions. This data is critical for

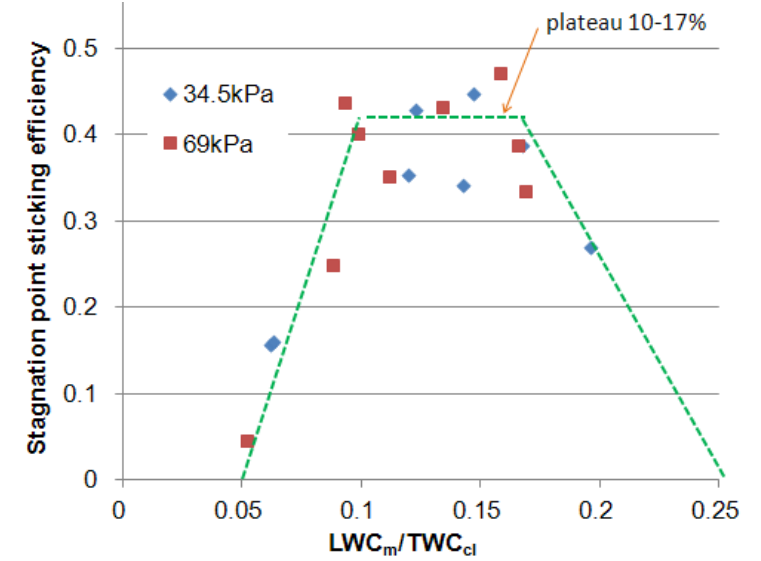

Fig. 2 - Ice crystal sticking efficiency vs melt ratio, with a plateau at 10-17\% [5]

understanding and modelling accretion physics in real-world conditions.

The research questions for this paper therefore comprise:
1. To what extent does a surface, heated to temperatures representative of the core compressor, contribute to particle melting?

2. What is the surface heat transfer enhancement over a range of icing and aerodynamic parameters?

3. Is it possible to use data on particle breakup dynamics to explain the heat transfer behaviour observed?

\section{NOMENCLATURE}

\section{Abbreviations}

\begin{tabular}{|c|c|}
\hline & \\
\hline AoA & Angle of Attack $\left(^{\circ}\right)$ \\
\hline $\mathrm{AC}$ & Alternating Current \\
\hline AIWT & Altitude Icing Wind Tunnel (NRC) \\
\hline CFD & Computational Fluid Dynamics \\
\hline DAQ & Data Acquisition system \\
\hline DPM & Discrete Phase Modelling \\
\hline HTA & Heat Transfer Amplifier \\
\hline IPC & Intermediate Pressure Compressor \\
\hline LE & Leading Edge \\
\hline LPC & Low Pressure Compressor \\
\hline MMD & Median Mass Diameter $(\mu \mathrm{m})$ \\
\hline MR & Melt Ratio (\%) \\
\hline NRC & National Research Council of Canada \\
\hline PID & Proportional-Integral-Derivative \\
\hline PIV & Particle Image Velocimetry \\
\hline RATFac & Research Altitude Test Facility \\
\hline RH & Relative Humidity (\%) \\
\hline SST & Shear Stress Transport \\
\hline TAT & Total Air Temperature $\left({ }^{\circ} \mathrm{C}\right)$ \\
\hline TFG & Thin Film heat flux Gauge \\
\hline TWC & Total Water Content $\left(\mathrm{g} / \mathrm{m}^{3}\right)$ \\
\hline \multicolumn{2}{|c|}{ Symbols } \\
\hline$a$ & Thickness, m \\
\hline$A$ & Area, $\mathrm{m}^{2}$ \\
\hline$c$ & Sound speed, $\mathrm{m} / \mathrm{s}$ \\
\hline$C_{p}$ & Specific heat capacity at constant pressure (J/kg.K) \\
\hline$C_{d}$ & Drag coefficient \\
\hline$d_{p}$ & Particle diameter $(\mu \mathrm{m})$ \\
\hline$D$ & Characteristic dimension (m) \\
\hline$h$ & Heat transfer coefficient $\left(\mathrm{W} / \mathrm{m}^{2} . \mathrm{K}\right)$ \\
\hline$k$ & Thermal conductivity (W/m.K) \\
\hline$\dot{m}$ & Mass flow rate $(\mathrm{kg} / \mathrm{s})$ \\
\hline$n$ & Sample number at time $\mathrm{t}$ \\
\hline$N$ & Total number of samples \\
\hline$P$ & Pressure $(\mathrm{Pa})$ \\
\hline$q$ & Heat flux $\left(\mathrm{W} / \mathrm{m}^{2}\right)$ \\
\hline$Q$ & Heat flow rate $(\mathrm{W})$ \\
\hline$R$ & Specific gas constant (J/kg.K) \\
\hline$t$ & Time (s) \\
\hline$T$ & Temperature (K) \\
\hline$v$ & Velocity $(\mathrm{m} / \mathrm{s})$ \\
\hline$x$ & Streamwise position (m) \\
\hline$y$ & Spanwise position (m) \\
\hline$z$ & Vertical position (m) \\
\hline$\alpha$ & Angle of attack $\left(^{\circ}\right)$ \\
\hline
\end{tabular}




\begin{tabular}{|c|c|}
\hline$\mu$ & Dynamic viscosity (Pa.s) \\
\hline$\rho$ & Density $\left(\mathrm{kg} / \mathrm{m}^{3}\right)$ \\
\hline$\sigma_{Y}$ & Yield strength $(\mathrm{Pa})$ \\
\hline$\tau_{\mathrm{p}}$ & Particle relaxation time (s) \\
\hline \multicolumn{2}{|c|}{ Subscripts } \\
\hline 0 & Total conditions \\
\hline 01 & Total conditions at inlet \\
\hline$\infty$ & Freestream conditions \\
\hline conv & Convective \\
\hline corr & Correlation \\
\hline dyn & Dynamic (pressure) \\
\hline enh & Enhancement (heat transfer) \\
\hline $\exp$ & Experimentally measured \\
\hline evap & Evaporation \\
\hline kin & Kinetic \\
\hline $\mathrm{K}$ & Kapton \\
\hline i & ice \\
\hline sub & Substrate \\
\hline surf & Surface \\
\hline sens & Sensible heating \\
\hline $\mathrm{p}$ & Particle \\
\hline $\mathrm{h}$ & Heater \\
\hline $\mathrm{Ti}$ & Titanium \\
\hline $\mathrm{w}$ & Water \\
\hline wall & Top surface of titanium layer (icing surface \\
\hline$w b$ & Wet bulb (temperature) \\
\hline $\mathrm{i}, \mathrm{j}$ & Local streamwise, spanwise position \\
\hline \multicolumn{2}{|c|}{ Groups } \\
\hline $\mathrm{Bi}$ & Biot number $=\frac{h a}{k}$ \\
\hline M & Mach number $=\frac{v}{c}$ \\
\hline $\mathrm{Nu}$ & Nusselt number $=\frac{h x}{k}$ \\
\hline $\operatorname{Pr}$ & Prandtl number $=\frac{\mu C_{p}}{k}$ \\
\hline $\operatorname{Re}$ & Reynolds number $=\frac{\rho v x}{\mu}$ \\
\hline St & Stanton number $=\frac{h^{\mu}}{\rho v C_{p}}$ \\
\hline Stk & Stokes number $=\frac{\tau_{p} v}{D}$ \\
\hline$\gamma$ & Particle energy quantity $=v d_{p}{ }^{2 / 3}, \mathrm{~m}^{5 / 3} / \mathrm{s}$ \\
\hline
\end{tabular}

\section{METHODOLOGY}

\section{Approach}

In order to determine the heat transfer enhancement in icing conditions it is necessary to be able to validate the measured convective heat flux in dry conditions. A flat plate design at variable angle of attack was therefore chosen as this is well covered in the open literature. A flat surface also avoids the complication of individual particles bouncing multiple times as may occur on a curved surface when ice is introduced.

To take steady state heat transfer measurements, the plate (substrate) was designed to be maintained at an elevated design point temperature, and be approximately isothermal through high thermal mass. Two nominal substrate temperatures of $25^{\circ} \mathrm{C}$ and $35^{\circ} \mathrm{C}$ were specified. These temperatures may be found in the core compressor under both cruise and descent idle operating conditions. They also allow a sufficient driving temperature difference with the air and ice, such that the mixed phase heat flux is significant and measurable. Dual layer thin film heat flux gauges (TFGs) were specified to measure surface heat flux.

Parameter ranges of interest to the ice crystal icing phenomenon, and specific to surface heat transfer, were defined as shown in Table 1.

\section{Table 1 - Experimentally tested parameter ranges}

\begin{tabular}{cc} 
Parameter & Range \\
\hline $\mathrm{M}$ & $0.1-0.5$ \\
\hline $\mathrm{P}_{\mathrm{dyn}}(\mathrm{kPa})$ & $5-13$ \\
\hline $\mathrm{MMD}(\mu \mathrm{m})$ & $20-80$ \\
\hline $\mathrm{AoA}\left({ }^{\circ}\right)$ & $10-30$ \\
\hline $\mathrm{TWC}\left(\mathrm{g} / \mathrm{m}^{3}\right)$ & $0.0-3.0$ \\
\hline $\mathrm{T}_{\text {sub }}\left({ }^{\circ} \mathrm{C}\right)$ & 25,35
\end{tabular}

\section{Facility}

The facility used in this study was the Altitude Icing Wind Tunnel (AIWT) at the National Research Council, Canada (NRC). This is a closed loop altitude facility that uses liquid nitrogen to freeze water particles generated by air blast atomization. The operating envelope and facility characterisation may be found in [8]. A schematic of the facility is shown in Fig. 3. The test section is $520 \mathrm{~mm} \times 330 \mathrm{~mm}$. There is a spatial variation in ice concentration across the tunnel area (i.e. the highest ice concentration may be found along the tunnel centreline). This profile was calibrated prior to the campaign and used in the data postprocessing routines. The aerodynamic and icing calibrations are available in [9].

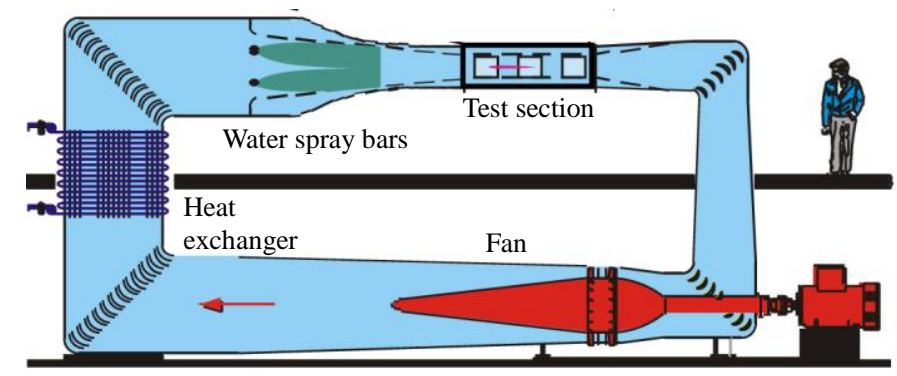

Fig. 3 - Schematic of the Altitude Icing Wind Tunnel (AIWT) [17]

\section{Test Piece}

The test piece is shown in Fig. 4. It consists of a copper flat plate substrate (Fig. 4a), of approximate dimensions $240 \mathrm{~mm} \times 100$ $\mathrm{mm} \times 32 \mathrm{~mm}$ with a $3 \mathrm{~mm}$ radius leading edge. The target heat transfer surface is a $150 \mathrm{~mm} \times 100 \mathrm{~mm}$ portion immediately downstream of the leading edge. The plate is heated from the underside (shown in Fig. 4b) using Omega high density heater cartridges, each delivering up to $100 \mathrm{~kW} / \mathrm{m}^{2}$. There are 24 heater cartridges ( $25.4 \mathrm{~mm}$ in length) installed in the underside, and two heater cartridges $(50.8 \mathrm{~mm}$ in length) installed in the leading edge portion (shown in Fig. 4c). Above the copper top surface 


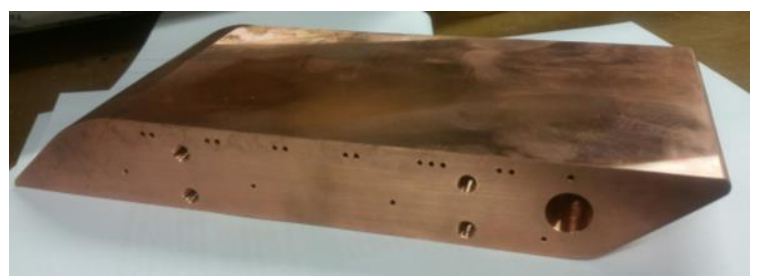

(a) Copper flat plate substrate

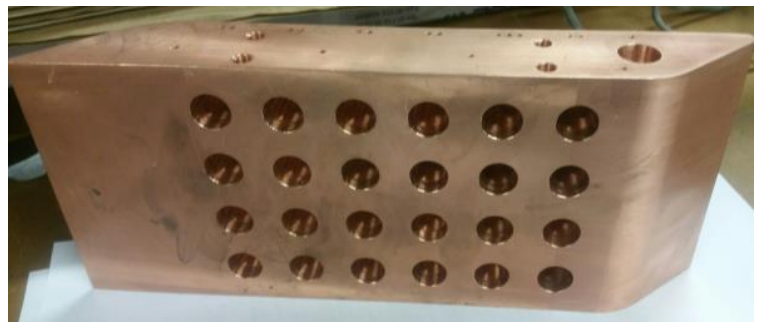

(b) Underside of copper substrate

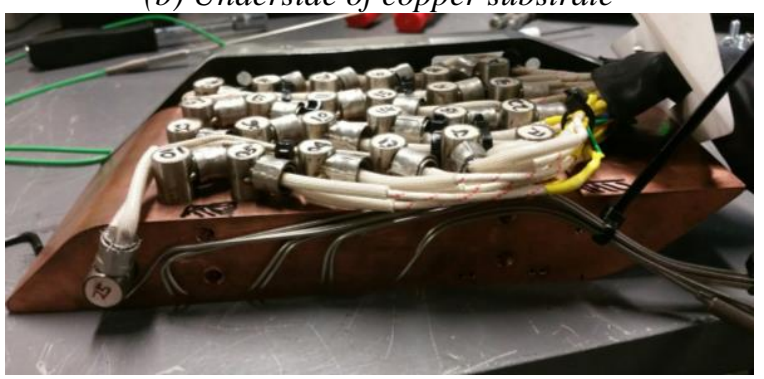

(c) Installation of thermocouples in the sidewalls and heater cartridges in the underside

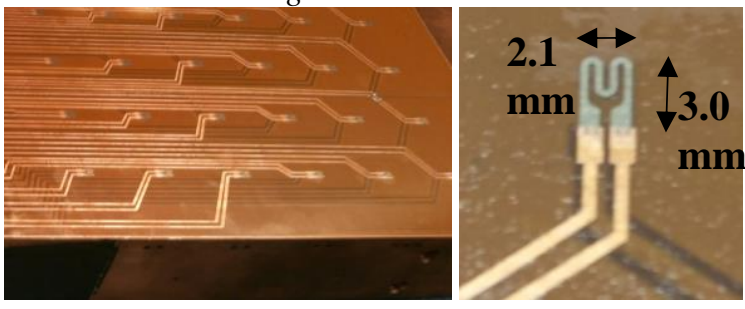

(d) Installation of Kapton layer with integrated thin film heat flux gauges (TFGs) on top surface

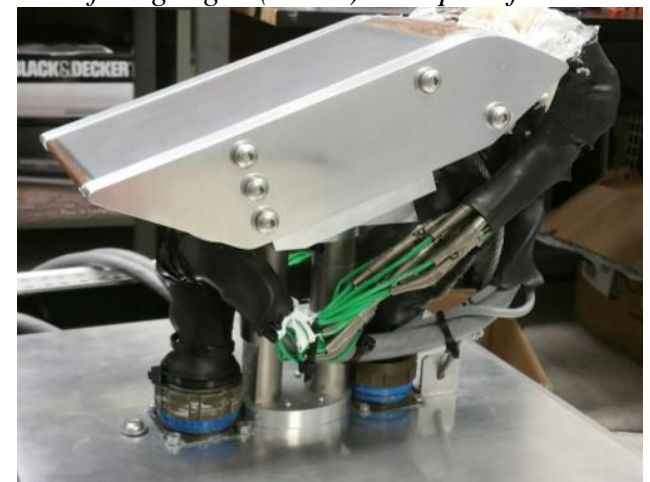

(e) Addition of Ti90-Al6-V4 layer, and mounting hardware

Fig. 4 - Test article during stages of assembly. The substrate leading edge is on the right in Figs $4 a$ and b; flow is left to right in Fig $4 e$ are two additional layers. These comprise a polyimide (Kapton) layer, onto which 24 dual layer thin film heat flux gauges (TFGs) are mounted (Fig. 4d). A simple skin depth calculation was used to specify that the top of the heaters should be no less than $8 \mathrm{~mm}$ from the TFG layer, to significantly reduce noise on the TFG signals due to $\mathrm{AC}$ mains interference.

The TFGs are of a design commonly used at Oxford University, and offer high speed temperature measurements with a bandwidth of over $100 \mathrm{kHz}$. Each consists of a thin $(\sim 40 \mathrm{~nm})$ layer of platinum, sputtered onto each side of a $50 \mu \mathrm{m}$ thick polyimide substrate, with $500 \mu \mathrm{m}$ wide copper tracks running back to the trailing edge. A constant current of $10 \mathrm{~mA}$ is applied to each gauge (which have a resistance of approximately 50 ohms) and the voltage is recorded. Using the method of Collins et al. [10], the temperature $T$ is calculated from the instantaneous voltage $V$ by Equation 1 .

$$
T-T_{1}=\frac{\left(V-V_{1}\right)\left(1+\alpha\left(T_{1}-T_{0}\right)\right)}{\alpha V_{1}}
$$

where $T_{1}$ and $V_{1}$ are the temperature and voltage respectively of a pre-test isothermal condition.

The temperature coefficient of resistance, $\alpha$, was found by calibration, whereby the test piece was immersed in a temperature controlled water bath. The length and type of connecting leads was kept constant between the calibration and the experiment. The resistance of each gauge, $R$, was measured using a digital multimeter at 18 isothermal conditions, in the range $0^{\circ} \mathrm{C}$ to $80^{\circ} \mathrm{C}$. A linear regression fit was applied to Equation 2 to find $\alpha . R_{0}$ is the gauge resistance at $T_{0}\left(0^{\circ} \mathrm{C}\right)$.

$$
R-R_{0}=\alpha R_{0}\left(T-T_{0}\right)
$$

The final, top layer of the test piece is a $400 \mu \mathrm{m}$ thick sheet of Ti90-Al6-V4 foil. This is representative of the material used in gas turbine compressor blades, and thus provides a representative coefficient of friction when in icing conditions. The complete test piece with mounting hardware is shown in Fig. 4e. A schematic of the test piece (not to scale) is shown in Fig. 5.

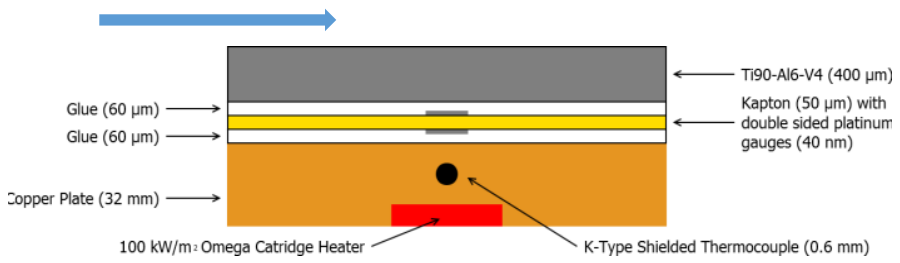

Fig. 5 - Schematic of test article (not to scale)

\section{Temperature Control}

The test piece is designed for both steady state and high frequency heat transfer measurements. To reference results easily to operating conditions, the test piece is designed to be isothermal both temporally and spatially. This is achieved using embedded heaters controlled using a PID negative feedback loop system. For each heater a K-type thermocouple embedded in the copper substrate between the top of the heater and icing surface provided the error signal for the controller. To achieve spatial 
temperature uniformity, the substrate was designed to have a Biot number below $\sim 0.1$ for all test cases $(\sim 0.039$ at the baseline flow condition). The spatial and temporal uniformity of the substrate temperature is shown in Fig. 6, for a dry run and a run at the maximum ice concentration of $3.0 \mathrm{~g} / \mathrm{m}^{3}$. The average temperature difference between the two runs is $\sim 0.6 \mathrm{~K}$. In both runs the plate is isothermal both spatially and temporally within $0.4 \mathrm{~K}$ (i.e. within the uncertainty of the thermocouples used).

The heat flux from the plate is expected to vary spatially, both due to falling heat transfer coefficients in the streamwise direction, and also due to the higher ice concentration at the centre of the plate compared with the outer edges. Therefore the true wall temperature will also vary spatially between tests at different conditions. It is calculated analytically post-test from the measured heat flux.

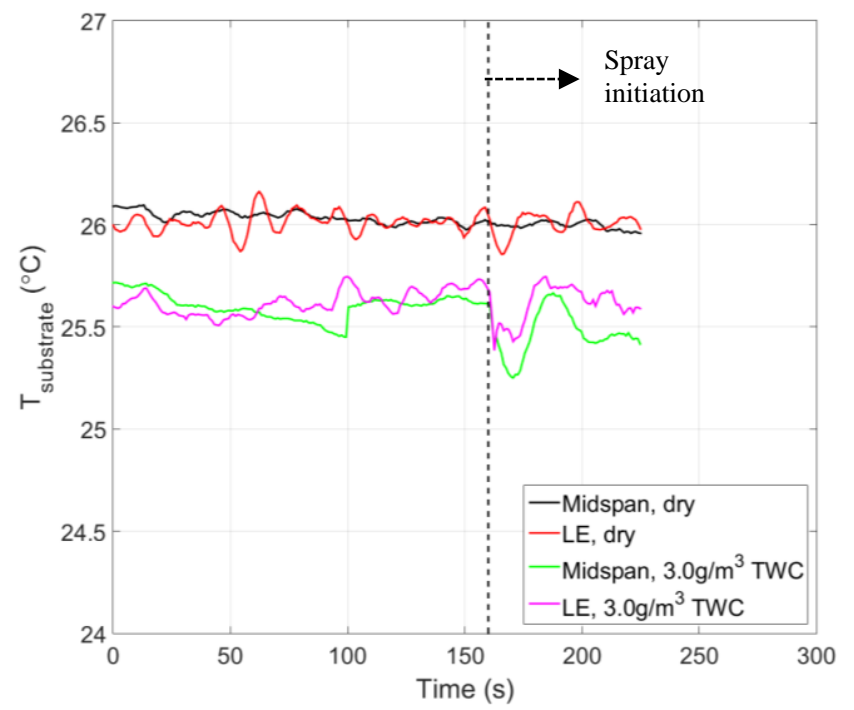

Fig. 6 - Spatial and temporal uniformity of substrate temperature (measured $2.5 \mathrm{~mm}$ below the copper top surface) for dry and maximum ice concentration runs

The test piece and heater control system designs were validated at the ice crystal wind tunnel at the University of Southern Queensland (USQ), Australia. This campaign was also used to develop a new design of thin film heat transfer amplifier (HTA). These boost high frequency, low amplitude temperature fluctuations to avoid quantisation errors when sampling. Details of their design is available in Anthony [11]. The new design of HTA combined the signal conditioning circuitry with a variable sample rate DAQ in the same unit. This proved to reduce signal noise by a factor of 6 compared with previous systems, when used in the same environment.

\section{Heat Transfer Modes}

The heat transfer balance in a steady state condition is given by Equation 3, with heat sources to the plate on the left hand side and heat sinks on the right hand side.

$q_{\mathrm{h}} A_{\mathrm{h}}+q_{\mathrm{kin}} A_{\text {surf }}=\left(q_{\mathrm{conv}}+q_{\mathrm{melt}}+q_{\mathrm{sens,ice}}\right.$

$$
\left.+q_{\text {sens,water }}+q_{\text {evap }}\right) A_{\text {surf }}+Q_{\text {losses }}+q_{\text {radiation }} A_{\text {plate }}
$$

The term $q_{\text {sens,ice }}$ is the heat required to raise the temperature of the incoming particles to the melting temperature, and $q_{\text {sens,water }}$ the heat required to raise the temperature of any meltwater to the wall temperature of the plate. However, evaluating these terms requires prior knowledge of the amount of melting that has occurred (if any). As this is unknown, it is most useful to use a combined mixed phase heat flux term, $q_{\text {mixed phase }}$. There is an additional heat source, $q_{\text {kin }}$, due to the kinetic energy of the incoming particles. If all the incoming energy is transferred (i.e. no bouncing), then it may be expressed as in Equation 4.

$$
q_{\text {kin }}=\frac{1}{2} \frac{\dot{m}_{\text {ice }}}{A} v_{\mathrm{n}}{ }^{2}=\frac{1}{2} \frac{T W C}{1000} v_{\infty}{ }^{3} \sin ^{2} \alpha
$$

At the highest flow speed, this term is the same order of magnitude as that of the convective heat flux. However, particle imaging using a PIV system indicated bouncing and shattering occurred at all flow speeds, so the actual magnitude of this term may be significantly lower. As it is difficult to quantify this, it is therefore also included in the $q_{\text {mixed phase }}$ term. This is given by Equation 5 .

$$
\begin{aligned}
q_{\text {mixed phase }}=q_{\text {conv }} & +q_{\text {melt }}+q_{\text {sens,ice }} \\
& +q_{\text {sens,water }}-q_{\text {kin }}
\end{aligned}
$$

The AIWT is a closed loop tunnel, and so evaporation of recirculating ice crystals causes the air to approach saturation conditions. Relative humidity $(\mathrm{RH})$ data from the tunnel (shown in Fig. 7) indicate that the tunnel reaches $85-90 \%$ humidity after the first run of the day. In subsequent runs (where data are captured), humidity initially drops to $80-85 \%$ as the tunnel is

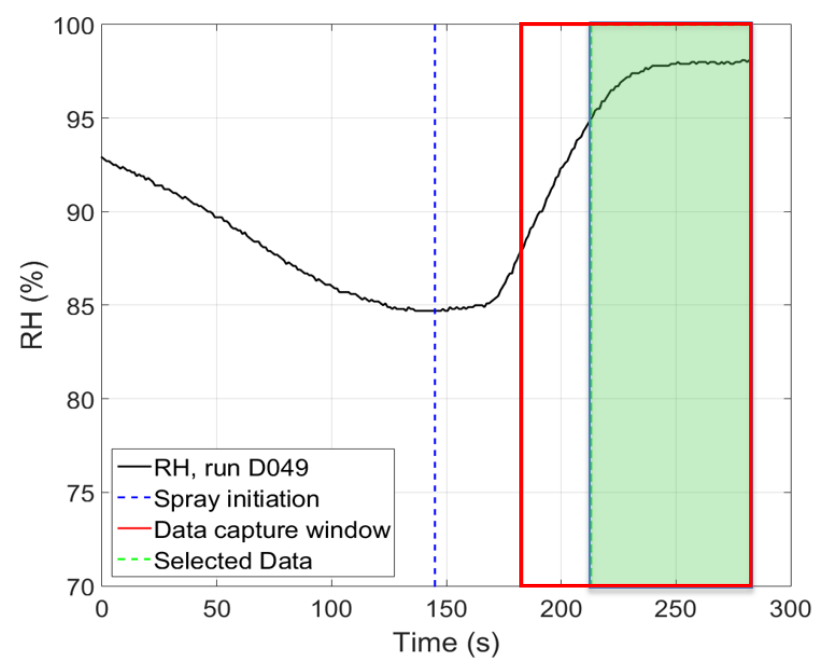

Fig. 7 - Relative humidity (\%) profile pre-and during run, with the data capture window highlighted

allowed to settle on the target condition in dry flow. When spray is initiated, the humidity rises again, typically remaining above $90 \%$ for the $100 \mathrm{~s}$ test duration. The lowest measured humidity during an icing run was $89 \%$. Therefore the $q_{\text {evap/sub }}$ term in Equation 3 was considered negligible. 
For the highest wall temperature, the radiative heat flux (assuming the surroundings were uniformly at the air total temperature) was two orders of magnitude lower than the dry convective heat flux, so $q_{\text {radiation }}$ was also neglected. The heat balance of Equation 3 therefore may be simplified as given in Equation 6.

$$
q_{\text {mixed phase }} A_{\text {surf }}=q_{\mathrm{TFG}} A_{\text {surf }}
$$

\section{Particle Glaciation}

A pre-requisite of the tests was that particles should be fully frozen out at the point of impact. This firstly allows replication of conditions early in the core compressor, and also allows in-air melting and evaporation to be neglected, provided the total air temperature was always below freezing and approximately equal to the particle temperature. Pre-test calibrations showed that full glaciation could be achieved at the baseline condition of Mach 0.4 and the highest TWC of $3.0 \mathrm{~g} / \mathrm{m}^{3}$, for particles with Median Mass Diameter (MMD) of $60 \mu \mathrm{m}$ or less. To ensure that particles remained frozen between the point of glaciation and the test piece, the total wet bulb temperature was maintained below -5 ${ }^{\circ} \mathrm{C}$ for all tests. This was achieved by maintaining the total dry bulb temperature at $-5^{\circ} \mathrm{C}$. With a typical relative humidity of $\sim$ $90 \%$, the total wet bulb temperature was therefore slightly below this, as shown in Fig. 8.

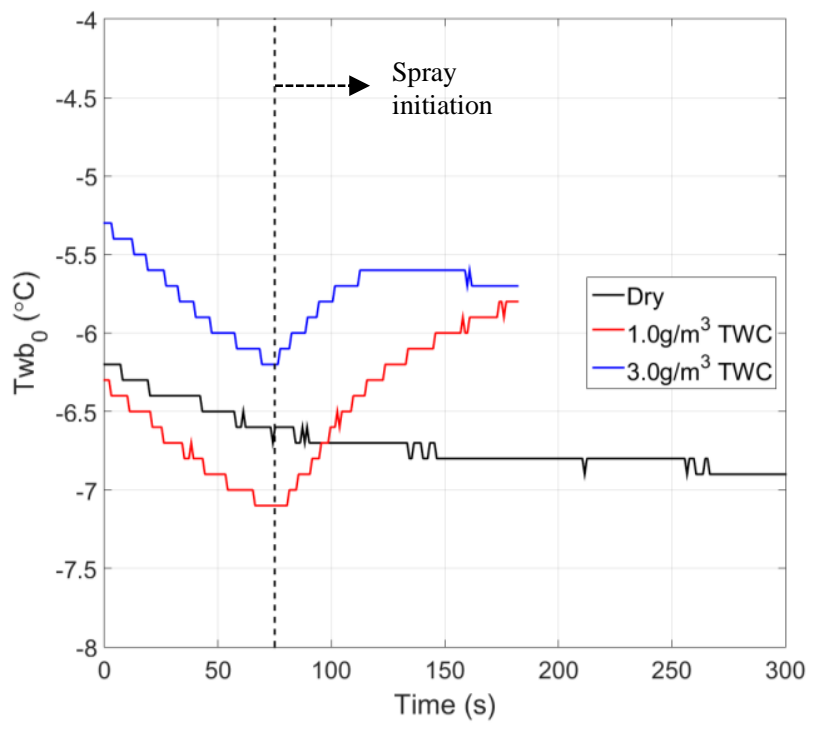

Fig. 8-Total wet bulb temperature profile pre-and during run

\section{Experimental Method \& Processing}

A test matrix was defined using the parameter ranges outlined in Table 1. For each condition, the test point was run in dry conditions followed by a run using the target TWC. Data was gathered for all tests under steady state conditions (100 s run time). A flow chart of the experimental process and postprocessing tasks is shown in Fig. 9.

For each test, $q_{\text {mixed }}$ phase was converted to Stanton number as shown in the flow chart. Stanton number may be described as the ratio of the total heat flux transferred into a fluid to the mass velocity weighted thermal capacity of the fluid, as shown in Equation 7.

$$
S t_{\exp }=\frac{h}{\rho v C_{\mathrm{p}}}=\frac{N u}{R e P r}
$$

Between dry and icing runs, the fluid composition changes. In icing runs, excess nitrogen (used in the liquid water freezeout)

(1) Measure the conditioned voltage signal from the thin film gauges, sampling at $4 \mathrm{MHz}$. Decimate the sampled data into memory at a rate of $1.93 \mathrm{kHz}$ over a run time of $100 \mathrm{~s}$. Measure aerodynamic parameters, RH and TWC, sampling at $1 \mathrm{~Hz}$.

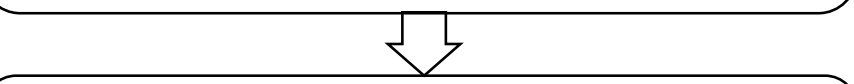

(2) Recover the true thin film voltage signal by removing the high frequency boost of the heat transfer amplifiers (HTAs).

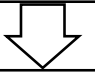

(3) Convert the thin film voltage signal to temperature using the water bath calibration method of Collins et al. [10]

Use temperature traces from both top and bottom gauges at position $i, j$ to perform a $1 \mathrm{D}$ conduction

$$
\bar{q}_{\mathrm{i}, \mathrm{j}}=\frac{1}{N} \sum_{n=1}^{n=N} q_{\mathrm{i}, \mathrm{j}}\left(t_{\mathrm{n}}\right)=\frac{1}{N} \sum_{n=1}^{n=N} k_{\mathrm{K}} \frac{T_{\mathrm{B}}\left(t_{\mathrm{n}}\right)-T_{\mathrm{T}}\left(t_{\mathrm{n}}\right)}{a_{\mathrm{K}}}
$$

where $T_{\mathrm{B}}$ is the temperature reading of the bottom TFG, $\& T_{\mathrm{T}}$ the reading of the top TFG, at sample $n$, time $t_{\mathrm{n}}$

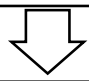

(5) Calculate the local wall temperature, and hence local enhanced heat transfer coefficient and Nusselt number

$$
T_{\mathrm{w}_{\mathrm{i}, \mathrm{j}}}=T_{\mathrm{T}_{\mathrm{avg}}}-\frac{\overline{\mathrm{q}}_{\mathrm{i}, \mathrm{j}}}{k_{\mathrm{Ti}}} a_{\mathrm{Ti}} ; h_{\mathrm{i}, \mathrm{j}}=\frac{\bar{q}_{\mathrm{i}, \mathrm{j}}}{T_{\mathrm{w}_{\mathrm{i}, \mathrm{j}}}-T_{0}} ; N u_{\mathrm{i}, \mathrm{j}}=\frac{h_{\mathrm{i}, \mathrm{j}} x_{\mathrm{i}, \mathrm{j}}}{k_{\mathrm{mix}}}(9)
$$

(6) Convert the calculated Nusselt number to Stanton number using measured flow parameters

$$
S t_{\exp _{\mathrm{i}, \mathrm{j}}}=\frac{h_{\mathrm{i}, \mathrm{j}}}{\rho_{\mathrm{mix}} v_{\infty} C_{\mathrm{p}_{\text {mix }}}}=\frac{N u_{\mathrm{i}, \mathrm{j}}}{R e_{\mathrm{i}, \mathrm{j}} \operatorname{Pr}}
$$

Fig. 9 - Flowchart of experimental procedure and postprocessing 
and water vapour also exist at the test piece surface. The relative mass flows of these components were used to define a mass fraction average of specific heat capacity and density. An overall thermal conductivity for the mixture was calculated using the method of Lindsay and Bromley [12].

The heat transfer enhancement was calculated by dividing the experimental Stanton number by its theoretical value in dry conditions (Equation 11), according to the empirical Nusselt number correlation of Motwani et al. [13] (Equation 12).

$$
S t_{\mathrm{enh}}=\frac{S t_{\mathrm{exp}}}{S t_{\mathrm{dry}, \mathrm{corr}}}=\frac{S t_{\mathrm{exp}} \operatorname{RePr}}{N u_{\mathrm{dry}, \mathrm{corr}}}
$$

where

$$
N u_{\text {dry,corr }}=\left\{\begin{array}{rr}
0.056\left(1-\frac{\alpha}{44.2}\right) R^{0.77}\left(\text { for } \alpha=0-15^{\circ}\right) \\
0.084 R e^{0.68} \quad\left(\text { for } \alpha=30-45^{\circ}\right)
\end{array}\right.
$$

This is valid for the Reynolds number range tested experimentally of $2 \times 10^{4}-3 \times 10^{5}$. A Bezier curve fit was used to interpolate between the correlations for angles of attack between 15 and $30^{\circ}$. Fig. 10 shows $N u_{\text {dry,corr }}$ plotted against local Reynolds number for angles of attack between 0 and $45^{\circ}$. A theoretical flat plate, turbulent flow Nusselt number correlation is also plotted. This is for the case of a very high aspect ratio plate at $0^{\circ}$ angle of attack.

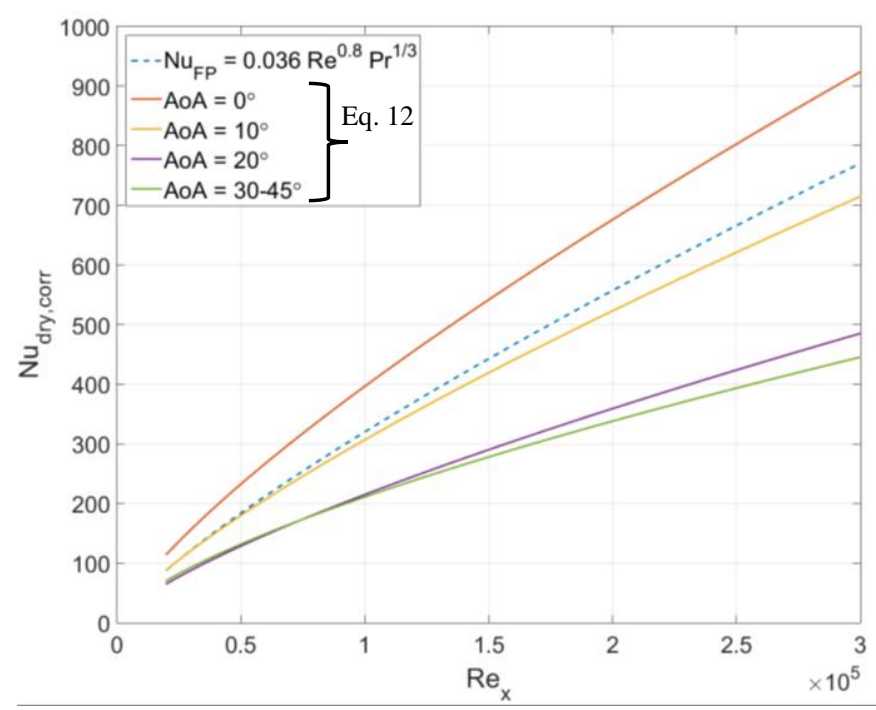

Fig. 10 - Nusselt number against local Reynolds number according to Equation 12, with a theoretical flat plate solution

\section{Uncertainty Analysis}

An uncertainty analysis was conducted using the Taylor Series Method described in Coleman and Steele [14]. A baseline test condition was selected, as shown in Table 2.
Table 2 - Uncertainty analysis of measured and derived

\begin{tabular}{|c|c|c|c|c|}
\hline Parameter & $\begin{array}{l}\text { Baseline } \\
\text { case value }\end{array}$ & $\begin{array}{l}\text { Uncertainty } \\
\text { (absolute) }\end{array}$ & $\begin{array}{l}\text { Uncertainty } \\
(\%)\end{array}$ & Source \\
\hline \multicolumn{5}{|c|}{ Measured parameters } \\
\hline $\mathrm{T}\left({ }^{\circ} \mathrm{C}\right)$ & -13.0 & 0.200 & 1.54 & [9] \\
\hline $\mathrm{T}_{\mathrm{TFG}}\left({ }^{\circ} \mathrm{C}\right)$ & 28.9 & 0.150 & 0.519 & \\
\hline $\mathrm{T}_{\text {sub }}\left({ }^{\circ} \mathrm{C}\right)$ & 35.0 & 0.500 & 1.43 & \\
\hline Altitude $(\mathrm{m})$ & 5490 & 12.6 & 0.229 & [9] \\
\hline $\mathrm{P}(\mathrm{Pa})$ & 44780 & 67.2 & 0.150 & [9] \\
\hline $\mathrm{M}$ & 0.40 & $6.60 \times 10^{-5}$ & 0.0165 & [9] \\
\hline $\mathrm{v}(\mathrm{m} / \mathrm{s})$ & 129.0 & 0.142 & 0.110 & [9] \\
\hline $\mathrm{RH}(\%)$ & 90.0 & 1.80 & 2.00 & [9] \\
\hline TWC $\left(\mathrm{g} / \mathrm{m}^{3}\right)$ & 1.00 & 0.200 & 20.0 & [9] \\
\hline $\operatorname{MMD}(\mu \mathrm{m})$ & 40.0 & 3.00 & 7.50 & [9] \\
\hline$\alpha\left(^{\circ}\right)$ & 20.0 & 0.100 & 0.500 & [15] \\
\hline \multicolumn{5}{|c|}{ Derived parameters } \\
\hline $\mathrm{q}_{\mathrm{TFG}}\left(\mathrm{W} / \mathrm{m}^{2}\right)$ & 4069 & 327 & 8.04 & \\
\hline $\mathrm{h}\left(\mathrm{W} / \mathrm{m}^{2} / \mathrm{K}\right)$ & 135.4 & 10.9 & 8.24 & \\
\hline $\mathrm{Nu}$ & 225.7 & 18.2 & 10.8 & \\
\hline $\mathrm{Re}$ & 172100 & 589 & 0.342 & \\
\hline $\mathrm{St}_{\exp }$ & 0.002472 & $1.51 \times 10^{-4}$ & 11.1 & \\
\hline $\mathrm{St}_{\text {corr }}$ & 0.002736 & $1.13 \times 10^{-4}$ & 4.13 & \\
\hline Stenh & 0.903 & 0.0550 & 11.5 & \\
\hline
\end{tabular}
parameters for baseline test condition

\section{NUMERICAL SETUP}

Numerical discrete phase simulations using Lagrangian particle tracking were used to qualitatively relate the observed heat transfer behaviour with particle trajectories in the test section. A flowfield solution was generated using FLUENT for the baseline aerodynamic case and a simplified 3D geometry, at angles of attack of $10^{\circ}$ and $20^{\circ}$. The $20^{\circ}$ geometry, generated in SolidWorks, and the mesh, generated in ICEM are shown in Fig. 11. A sensitivity analysis to turbulence model was conducted. The particle collection efficiency on the impact surface was selected as the parameter under test. It is important to note that

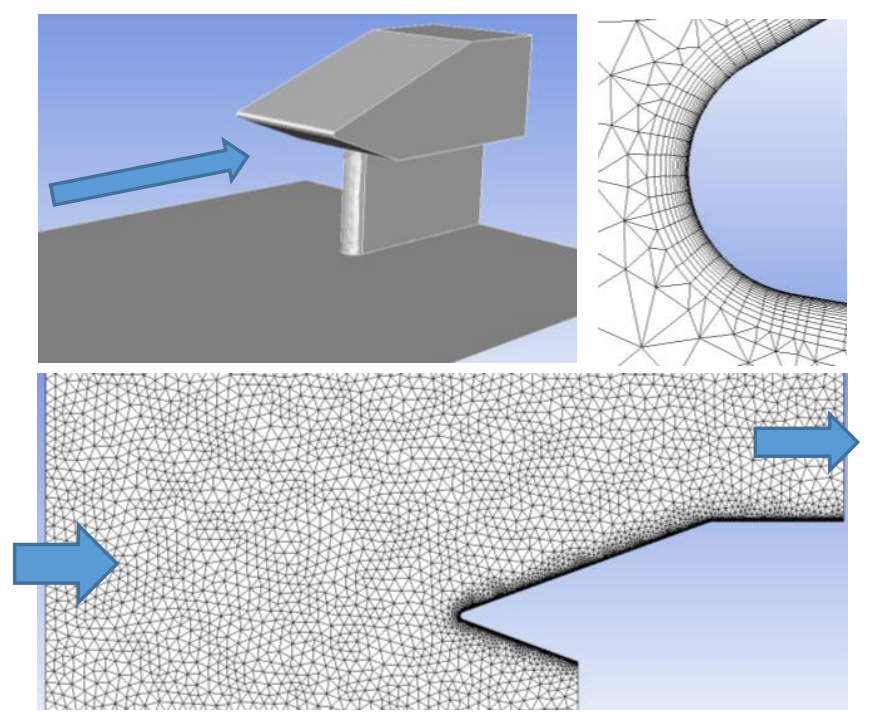

Fig. 11 - Anticlockwise from top left: simplified solid model used in computation; $2 D$ slice of computational domain at midspan; mesh refinement at the leading edge 
the effect of turbulent dispersion on particle trajectory was expected to be minimal; ballistic particles will pass through eddies with little deviation, whereas smaller particles are more likely to be deflected due to the potential field of the test article. The models tested comprised of k- $\varepsilon$ with standard wall functions applied, the standard k- $\omega$ model and the k- $\omega$ SST model, as shown in Fig. 12. In all cases one-way aerodynamic coupling was assumed in the discrete phase model.

The maximum discrepancy in particle collection efficiency between models is below $2 \%$. Using a $\mathrm{k}-\omega$ formulation (thus resolving down to the wall) was computationally practical for the domain size. The SST model was selected, thus utilising the $\mathrm{k}-\varepsilon$ model in the mainstream to define the bulk particle trajectories. The effect of modelling two-way aerodynamic coupling was also investigated, as shown in Fig. 12. The difference in collection efficiency between one and two-way coupling was less than $0.5 \%$, and therefore one-way coupling was chosen for all other tests. Sensitivity to the Lagrangian step length - defining the length of the time step over which the particle equations of motion are integrated - was halved from the standard length of $1 \mathrm{~mm}$ to $0.5 \mathrm{~mm}$. At Mach 0.4 , this corresponds to a time step of approximately $2 \mathrm{~ms}$. The discrepancy in collection efficiency between the two cases was again less than $0.5 \%$, thus the original value of $1 \mathrm{~mm}$ was maintained.

A mesh sensitivity analysis was also conducted as shown in Fig. 12. Four computational domains, of 1.0M, 1.9M, $3.7 \mathrm{M}$ and $7.2 \mathrm{M}$ cells were generated. The difference in collection efficiency for the $3.7 \mathrm{M}$ and $7.2 \mathrm{M}$ was approximately $0.2 \%$, so the $3.7 \mathrm{M}$ cell mesh was used in all subsequent simulations. The maximum $\mathrm{y}^{+}$value on the test piece surface was 4.75 .

Inlet Mach number, total pressure and total temperature were matched to the baseline condition in Table 2. Details of the computational domain and setup for the fluid phase are

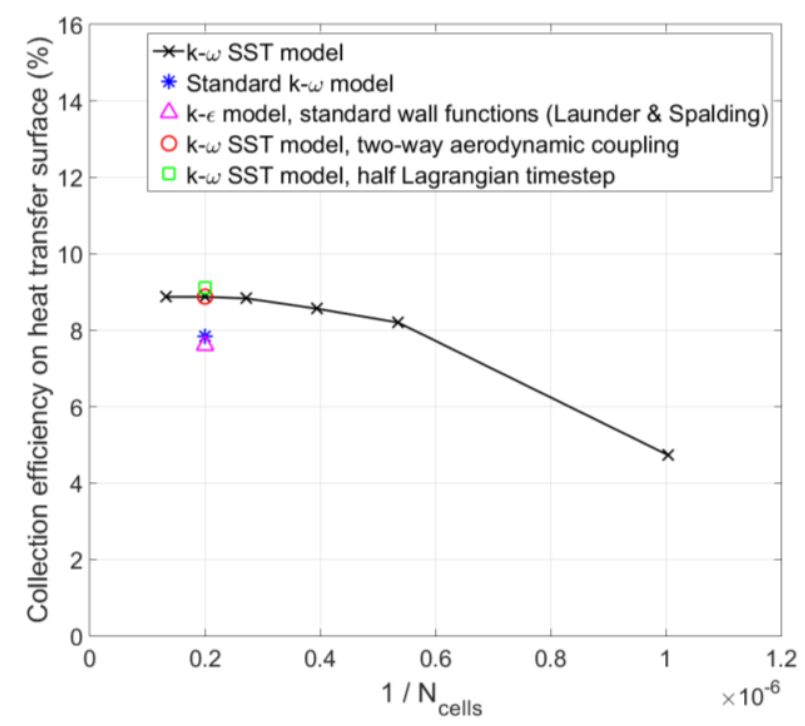

Fig. 12 - Sensitivity analysis on particle collection efficiency for varying computational setup summarised in Table 3, and for the discrete (particle) phase in Table 4.

Table 3 Computational domain and boundary conditions

\begin{tabular}{ll} 
Mesh & Unstructured, 3.7m cells \\
\hline Boundary layer mesh & 15 prism layers \\
\hline Maximum wall y+ & 4.75 \\
\hline Inlet profile & Fully developed turbulent pipe flow \\
\hline Freestream Tu $(\%)$ & $0.6[9]$ \\
\hline Turbulence model & $\mathrm{k}-\omega \mathrm{SST}$ \\
\hline$M_{\infty}$ & 0.400 \\
\hline Altitude $(\mathrm{m})$ & 5490 \\
\hline$T_{01}(\mathrm{~K})$ & 268.2 \\
\hline
\end{tabular}

Table 4 - Discrete phase modelling (DPM) parameters

Particle tracking method Lagrangian

\begin{tabular}{ll}
\hline Particle diameters $(\mu \mathrm{m})$ & $10,20,40,60$ \\
\hline Particle density $\left(\mathrm{kg} / \mathrm{m}^{3}\right)$ & 940 \\
\hline Body forces & $\begin{array}{l}\text { Gravity, drag, pressure } \\
\text { gradient, Saffman's lift force }\end{array}$ \\
\hline Drag coefficient & Spherical \\
\hline Wall interaction & Bounce \\
\hline Lagrangian step length $(\mathrm{mm})$ & 1.0 \\
\hline Aerodynamic coupling & $1-$ way \\
\hline Thermal coupling & None
\end{tabular}

A spherical drag coefficient was applied. The ice particles in the test facility are generated by freezing out water droplets from an air blast atomizer, so this is a reasonable assumption.

\section{RESULTS}

\section{Conventions}

In the following discussion, the streamwise direction is taken as the flow direction resolved parallel to the test piece surface. For most cases, this is $20^{\circ}$ to the axial direction. In agreement with NRC convention, the left hand side of the tunnel or test piece when facing downstream is the starboard side, and vice versa for port side.

\section{Test piece aerothermal validation}

(i) Heat transfer in dry conditions

The dry-flow heat transfer at a range of streamwise positions was first validated against Equation 12, as shown in Fig. 13. Agreement between the experimental data and correlation is within $10 \%$. 


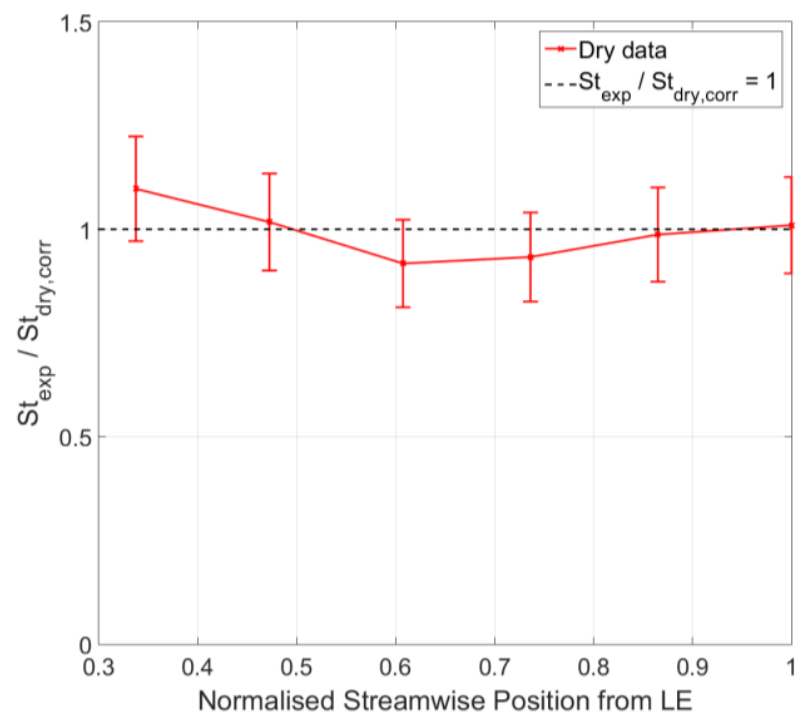

Fig. 13 - Validation of measured Stanton number for all streamwise positions

Fig. 14 shows a comparison of experimental and correlation data for heat transfer at varying plate angles of attack. This was again done in dry conditions at the same baseline condition. Agreement is again within 10\%.

The Reynolds number based on streamwise position is in the range $6 \times 10^{4}-3 \times 10^{5}$ for the baseline case defined in Table 2, and thus is likely to be transitional towards the rear of the plate. Motwani et al. used tripwires to promote a turbulent boundary layer when generating the correlations given in Equation 12. However, they also found the state of the boundary layer to be dependent upon the angle of attack. The 0.77 exponent on Reynolds number in the first part of Equation 12 is indicative of a fully turbulent boundary layer. This is attributed to a separation bubble just downstream of the leading edge causing transition. As angle of attack increases the Nusselt number decreases for a given Reynolds number. This is

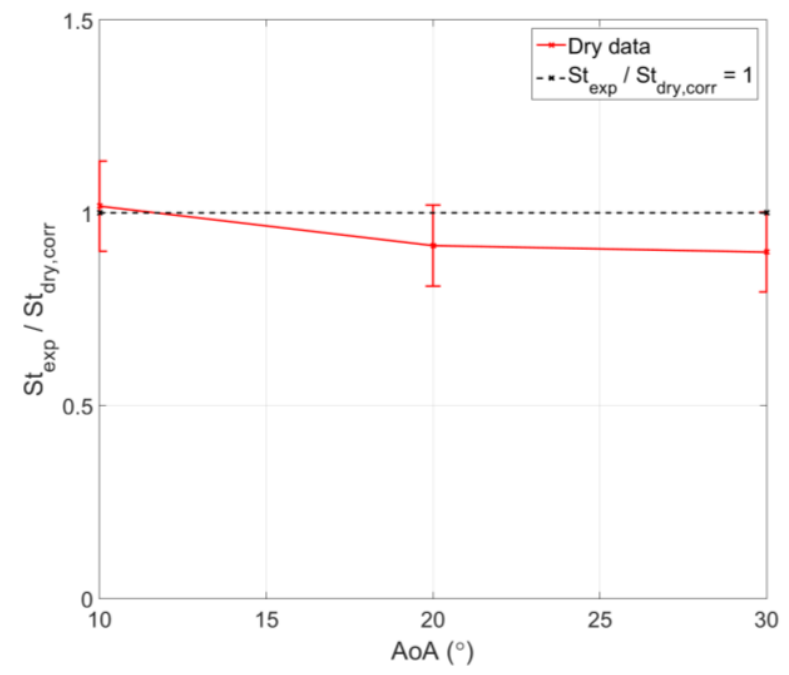

Fig. 14 - Validation of measured Stanton number for all angles of attack attributed to the separation bubble decreasing in size as angle rises, as an increasingly favourable pressure gradient is established. The reattachment location therefore moves upstream. Increasing angle of attack still further results in relaminarisation, as indicated by the 0.68 exponent in the second part of Equation 12.

Fig. 15 shows contours of velocity for the $10^{\circ}$ angle of attack numerical solution. A separation bubble is clearly visible immediately downstream of the leading edge, in agreement with Motwani et al. This separation is eradicated when the angle is raised above $20^{\circ}$, compared to above $30^{\circ}$ for Motwani et al. The discrepancy in Fig. 14 between correlation and experiment at these values could be attributed to this difference.

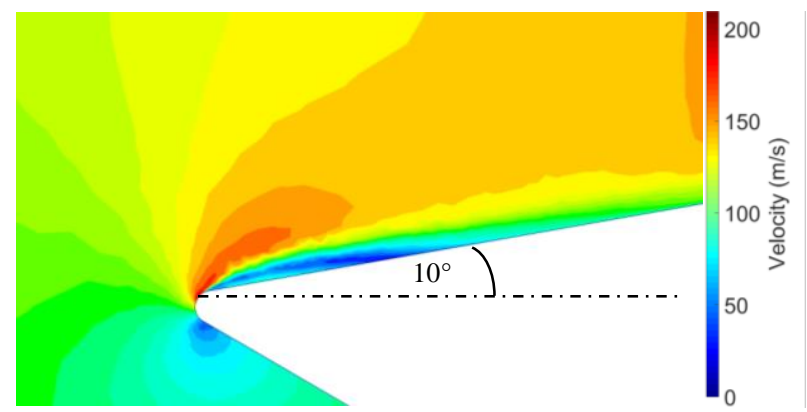

Fig. 15 - Velocity contours at midspan for the $10^{\circ}$ angle of attack case, baseline flow condition. Flow is left to right

\section{(ii) Spanwise variation in TWC}

The plate was characterised in icing conditions using a series of runs at the baseline aerodynamic condition given in Table 2 and a TWC of $0.5 \mathrm{~g} / \mathrm{m}^{3}$. Fig. 16 shows a calibration plot of TWC over the central tunnel area, at a nominal injected TWC of $0.5 \mathrm{~g} / \mathrm{m}^{3}$, a particle MMD of $40 \mu \mathrm{m}$ and freestream velocity of $90 \mathrm{~m} / \mathrm{s}$ [9]. Overlaid as black circles are the positions of the 24 thin film gauges, with the streamwise position mapped to the 'vertical' (Z) direction using the plate angle of attack of $20^{\circ}$.

For all particle diameters used, heat transfer enhancement readings from the two inner rows of TFGs were always within $5 \%$ of each other at a given streamwise position. The outer rows of gauges suffer from a reduction in TWC due to the profile in the tunnel (especially for the port side), sidewall

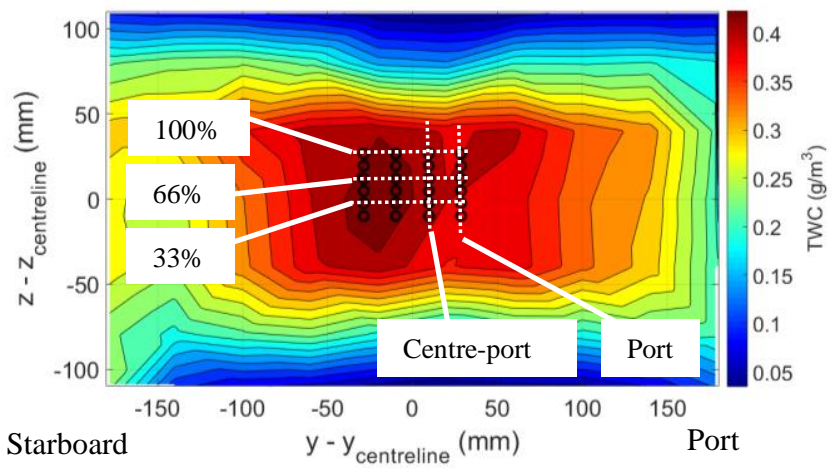

Fig. 16 - Profile of total water content over the central tunnel area [8], with the TFG locations overlaid as black circles. 33, 66 and $100 \%$ streamwise position gauges are highlighted 
heat loss and also particle deflection away from the test piece due to its own potential field. Fig. 17 shows particle tracks for (a) 10 $\mu \mathrm{m}$ and (b) $40 \mu \mathrm{m}$ diameter particles, using the flowfield solution described in Table. The particles are injected along a line that is parallel to the most port gauges (also shown on the figure). At a diameter of $10 \mu \mathrm{m}$, particles are well entrained in the flow, and are deflected around the sidewalls. The only impingements occur on or immediately after the leading edge. In the $40 \mu \mathrm{m}$ case (the same nominal diameter as used in the calibration data in Fig. 16), particle deflection increases in the streamwise direction and is significant at the $100 \%$ streamwise position. As a result, TWC impinging on the plate is locally reduced. It was therefore preferable when comparing between test cases to use an average of the readings of the two central gauges, at a given streamwise position. Particle deflection will of course occur for these rows also, albeit with a smaller spanwise component. The effect of this for a range of particle sizes is covered in the following section.

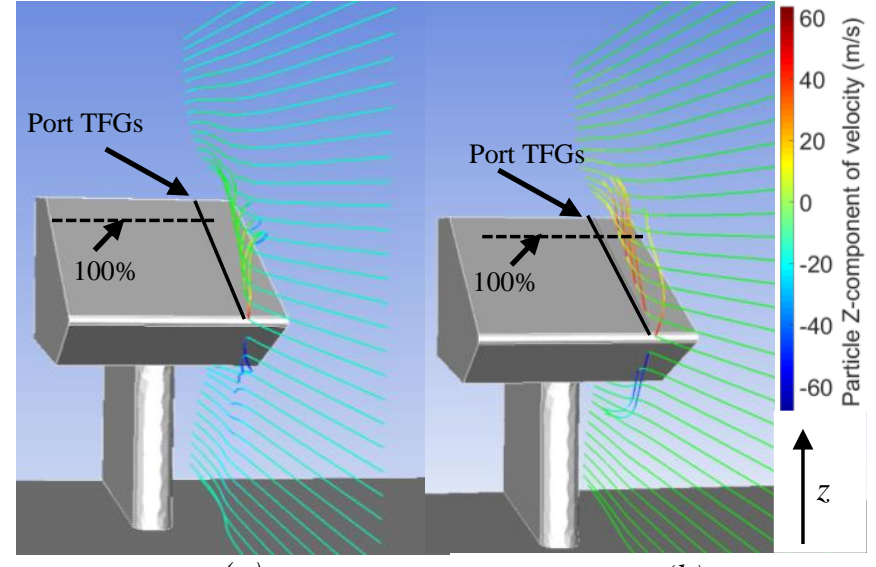

(a)

(b)

Fig. 17 - Particle traces for (a) $10 \mu \mathrm{m}$ particles and (b) $40 \mu \mathrm{m}$ particles, injected in line with the port row of TFGs. Tracks are coloured by particle velocity in the $Z$ (vertical) direction. Baseline aerodynamic condition; flow is into the page

(iii) Streamwise variation in TWC for central gauges

Particle studies were conducted using the same setup as described in Table 3, with particles this time injected parallel to the centre-port row of gauges (highlighted in Fig. 16). Particle trajectory behaviour is approximately symmetrical with the centre-starboard location.

Fig. 18 shows the streamwise TWC distribution for particles with MMD of 10, 20 and $40 \mu \mathrm{m}$. The solid lines denote the distribution if CFD-predicted particle trajectories are only considered, with a uniform TWC profile injected. The distribution was determined by taking the time - averaged particle concentration at a plane immediately upstream of the plate surface. For these studies, the plate surface was assumed to trap all impinging particles, to prevent bouncing particles from passing back through the measurement plane. The dashed lines show the combined effect of particle trajectories and the nonuniform TWC profile of the tunnel. This is therefore the TWC profile that the plate 'actually' sees. The data shows that at the leading edge (LE), where the potential field effect of the plate is minimal, at least $60 \%$ of all particles injected impinge (albeit at increasingly shallow angles as particle diameter decreases). By the $66 \%$ streamwise row of gauges, the concentration of 10 and $20 \mu \mathrm{m}$ particles has fallen to approximately $5 \%$ and $20 \%$ of the injected TWC respectively. Conversely, for $40 \mu \mathrm{m}$ particles, over $80 \%$ of particles impinge on the $66 \%$ streamwise gauge row. Additionally, there is only a small TWC reduction $(\sim 6 \%)$ across the length of the plate. Two additional datasets are also plotted, with the aim of investigating how the concentration profiles are expected to change as the conditions are varied from the baseline case (i.e. as points from the test matrix are run). The first of these is the case of an elevated TWC, raised from $0.5 \mathrm{~g} / \mathrm{m}^{3}$ to $1.5 \mathrm{~g} / \mathrm{m}^{3}$. The maximum difference between the cases is $3 \%$ of the injected TWC. The second additional line corresponds to a test run at Mach 0.1, which more importantly is the lowest Reynolds number tested experimentally. In this case the data diverges from the baseline aerodynamic condition (Mach 0.4).

This behaviour can be described using the particle Stokes number. Particles with a Stokes number much greater than unity will tend to follow the flow poorly - particularly in regions of high curvature or acceleration - and are termed ballistic. For Stokes numbers of much less than unity, particles tend to follow the flowfield well - i.e. with small or negligible slip velocities. It is given by

$$
S t k=\frac{\tau_{\mathrm{p}} v}{D}
$$

where

$$
\tau_{\mathrm{p}}=\frac{4}{3} \frac{\rho_{\mathrm{p}} d_{\mathrm{p}}{ }^{2}}{\mu} \frac{1}{\operatorname{Re} C_{\mathrm{d}}}
$$

Stokes numbers were calculated for the three MMDs by using the baseline flow condition to estimate the fluid relaxation time, and the nominal particle diameter to estimate the particle relaxation time. Stokes numbers for the cases shown in Fig. 18 are given in Table 5.

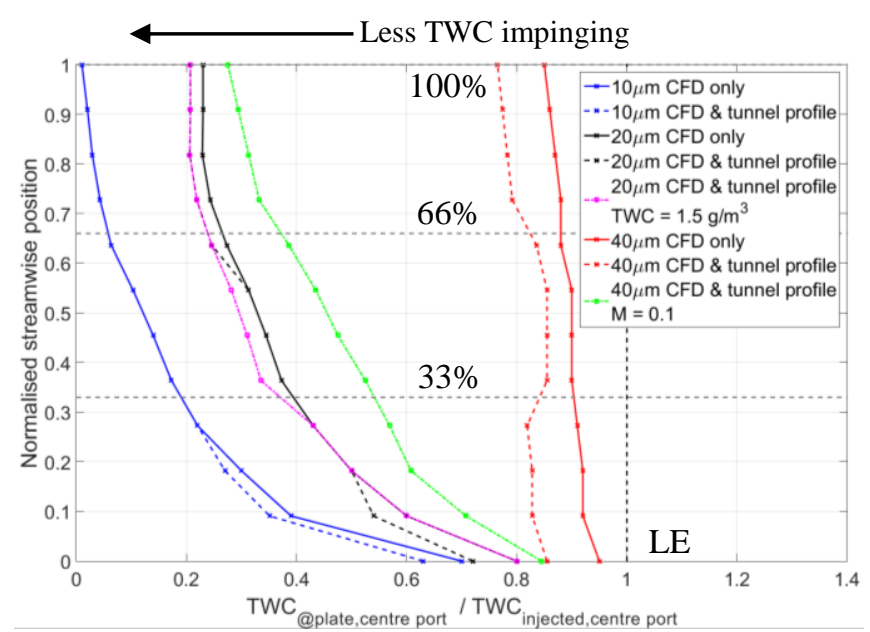

Fig. 18 - TWC impinging on the plate as a fraction of TWC injected, against streamwise location. Baseline aerodynamic condition and $T W C=0.5 \mathrm{~g} / \mathrm{m}^{3}$ unless otherwise stated 
Table 5 - Particle Stokes number for the test conditions given in Fig. 17

\begin{tabular}{ccc} 
MMD $(\mu \mathrm{m})$ & Mach & Stokes number $($ Stk $)$ \\
\hline 10 & 0.4 & 0.0761 \\
\hline 20 & 0.4 & 0.305 \\
\hline 40 & 0.4 & 1.22 \\
\hline 40 & 0.1 & 0.334
\end{tabular}

As may be expected from the trends in Fig. 18, 10 and $20 \mu \mathrm{m}$ particles have a Stokes number of less than unity at Mach 0.4, whilst for $40 \mu \mathrm{m}$ particles it is less than unity at Mach 0.1 but greater at Mach 0.4 .

The $66 \%$ streamwise gauge row was selected for use in comparing between test cases. The $33 \%$ row may also have been used. The $100 \%$ row sees a lower TWC due to the variation in the tunnel profile. It is important to note that in the following results and discussion, the TWC values stated refer to the nominal (injected) values - not the TWC that is present at the plate.

\section{(iii) Repeatability Studies}

Three tests conducted on three separate days using the baseline case in Table 2 showed measured values of Stanton number repeatable within $\sim 8 \%$ for the dry runs and $\sim 11 \%$ for the icing runs.

\section{Steady state heat transfer enhancement results (i) Effect of Total Water Content (TWC)}

Fig. 19 shows Stanton number enhancement against varying TWC. Aerodynamic conditions were held constant and TWC was varied between dry conditions $\left(0 \mathrm{~g} / \mathrm{m}^{3}\right)$ and $3.0 \mathrm{~g} / \mathrm{m}^{3}$. Plotted as dashed lines are theoretical values of Stanton number enhancement, at a range of melt ratios (MR). On a line of $10 \%$ $\mathrm{MR}$, for example, $10 \%$ of the incoming mass flow of ice is assumed to be melted by impact with the plate. The experimentally calculated wall temperature is used at each value of TWC to calculate Stanton number. Thus, where the experimental data line intersects the theoretical lines indicates the expected particle melt ratio. The figure indicates that the total heat flux is approximately linear with increasing TWC. Up to $3.0 \mathrm{~g} / \mathrm{m}^{3}$, a particle melt ratio of $30-40 \%$ would be expected. It is worth noting that as TWC rises, wall temperature falls (although the copper substrate temperature is approximately constant).

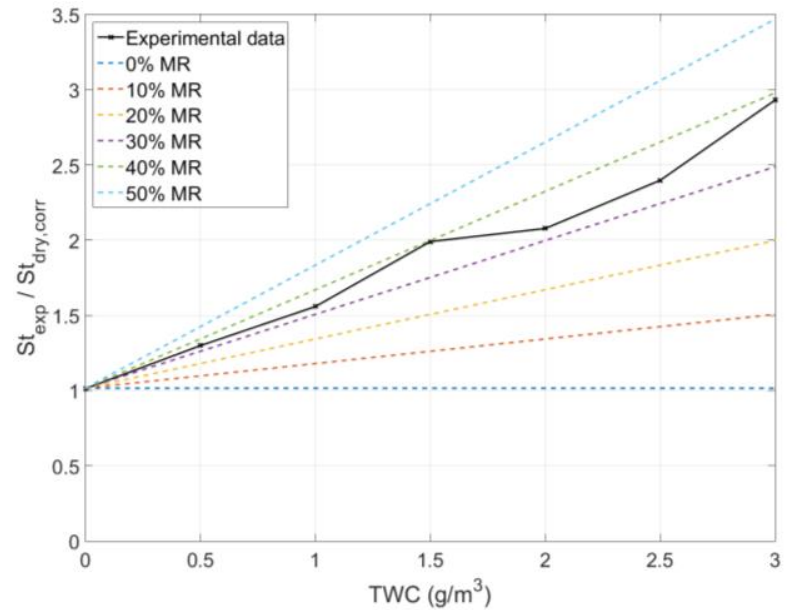

Fig. 19 - Stanton number enhancement against total water content, baseline aerodynamic condition

The calculated wall temperature for the same tests are plotted in Fig. 20. The driving temperature difference of the convective heat flux is reduced by approximately $6{ }^{\circ} \mathrm{C}$ between the dry case and the heaviest icing case $\left(3.0 \mathrm{~g} / \mathrm{m}^{3} \mathrm{TWC}\right)$. Taking the heat transfer coefficient from the dry case, this approximates to a reduction of $2 \mathrm{~kW} / \mathrm{m}^{2}$ between the two cases. Thus, if the total heat transfer enhancement in Fig. 19 is linear, heat flux to the ice and water must rise non-linearly to cancel out this reduction. One explanation for this is the development of a surface water film at high TWCs. The effect of this is twofold. Firstly, surface-water conduction increases the overall heat transfer, and secondly the impact time of impinging particles is increased as they are 'held' in the water layer.

Runs were repeated at a number of selected test points, with the aim of imaging particle impacts. A Particle Imaging Velocimetry (PIV) method was used, details of which may be found in Fuleki et al. [16]. In the future, the data will be used to build bounce and shatter models. It is used here to qualitatively relate the impact behaviour with the heat transfer measured. Two output images are shown in Fig. 21 and Fig. 22, with TWCs of $0.5 \mathrm{~g} / \mathrm{m}^{3}$ and $2.0 \mathrm{~g} / \mathrm{m}^{3}$ respectively. Both show a collection of secondary particles post-impact, and were captured approximately 3 minutes after spray was initiated. In both cases the baseline aerodynamic condition was used. As PIV uses two concurrent images to calculate particle velocity and size distribution, these two images are overlaid. Any given particle from the first image is coloured black and the same particle in the second image is coloured white. There is clear evidence of particle shattering in Fig. 21, as well as micron-scale spherical particles, indicative of water droplets. The largest secondary particle is approximately $50 \mu \mathrm{m}$, and the smallest under $5 \mu \mathrm{m}$. Fig. 22 shows a shattering and splashing event, with the splash pattern clearly visible in the first (black) image. The images suggest that a water film has developed when TWC $=2 \mathrm{~g} / \mathrm{m}^{3}$ but has not at $0.5 \mathrm{~g} / \mathrm{m}^{3}$. 


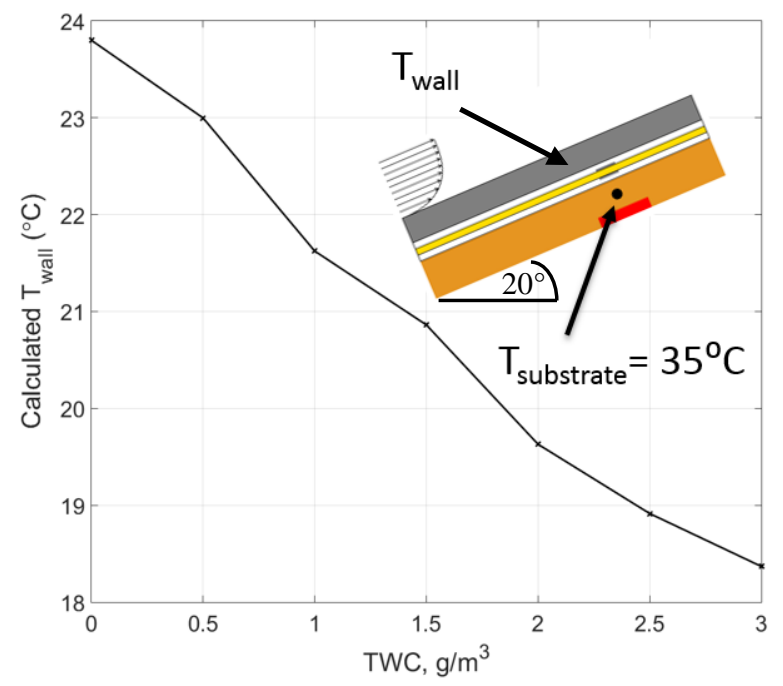

Fig. 20 - Wall temperature vs total water content. Schematic of test piece inset

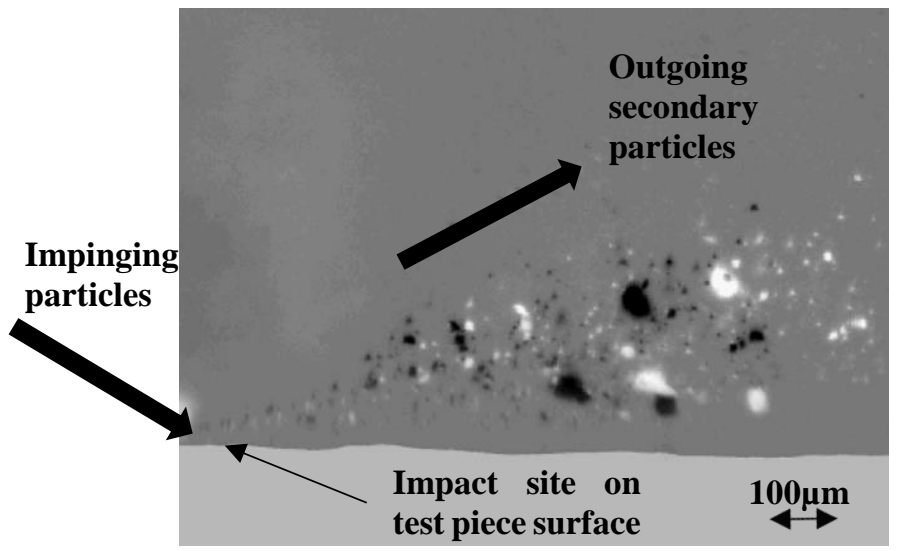

Fig. 21 - PIV image, showing a shattering event. $M M D=60 \mu \mathrm{m}, T W C=0.5 \mathrm{~g} / \mathrm{m}^{3}$

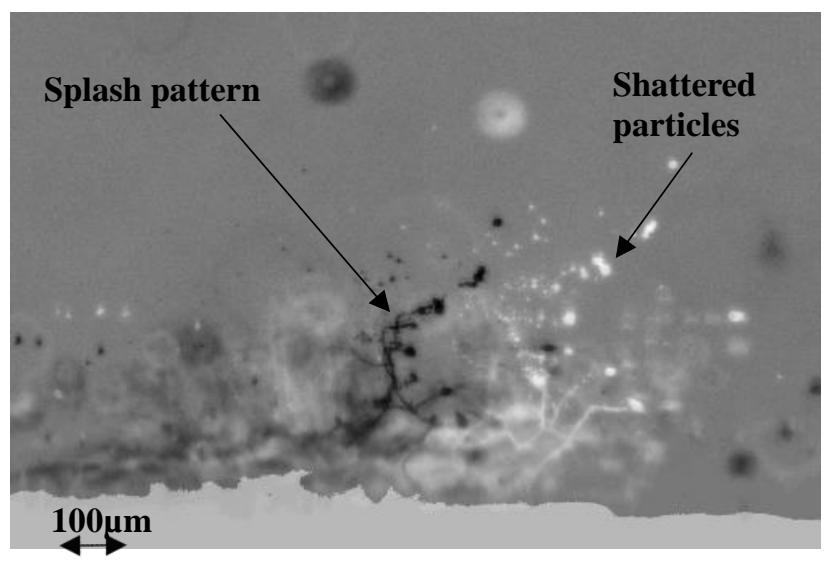

Fig. 22 - PIV image, showing a splashing event. $M M D=60 \mu \mathrm{m}, T W C=2.0 \mathrm{~g} / \mathrm{m}^{3}$

\section{(ii) Effect of Particle Diameter}

Fig. 23 shows data for runs conducted at Median Mass Diameters (MMDs) in the range $10-80 \mu \mathrm{m}$. All other conditions were maintained at the baseline values in Table 2. Stanton number enhancement is plotted in black and the particle Stokes number in red on the right hand axis.

The data shows that there is negligible heat transfer enhancement for particles of 10 and $20 \mu \mathrm{m}$ MMD, corresponding with Stokes numbers less than unity. Fig. 18 shows that by the $66 \%$ streamwise row of gauges, where the data in Fig. 23 is taken, the concentration of 10 and $20 \mu \mathrm{m}$ particles has fallen to approximately 5\% and $20 \%$ of the injected TWC respectively. This corresponds to a TWC of $0.05 \mathrm{~g} / \mathrm{m}^{3}$ and $0.2 \mathrm{~g} / \mathrm{m}^{3}$ respectively. These levels are sufficiently low that negligible heat transfer enhancement is measured, which is supported by the data shown in Fig. 19.

Conversely, for particles with MMDs of $40 \mu \mathrm{m}$ and above, the Stokes number exceeds unity and so particles are more ballistic in nature, and thus likely to impinge on the inclined heat transfer surface. It should be noted that at $80 \mu \mathrm{m}$ MMD, full freezeout of the particles could not be assured, so this data point may be an underestimate of the true heat transfer enhancement.

TWC, air velocity and air density were held constant throughout the tests, so the mass flow rate of ice impinging on the plate is constant. The pressure in the air blast atomizer was varied to obtain many small particles, or fewer large particles. If particles are assumed ballistic for any MMD above $40 \mu \mathrm{m}$, then the increasing Stanton number enhancement for larger particles implies that impact dynamics are an important driver in heat transfer. Roisman et al. [7] gave a theoretical particle impact time as

$$
t_{\max } \approx \frac{d_{\mathrm{p}_{0}} \sqrt{\rho}}{2 \sqrt{\sigma_{\mathrm{Y}}}}
$$

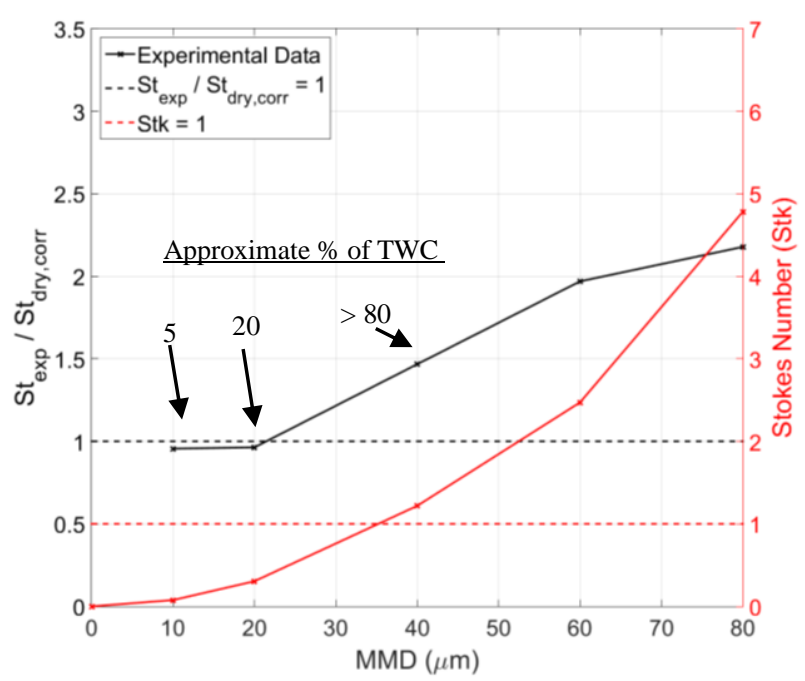

Fig. 23 - Stanton number enhancement against particle diameter (MMD), baseline aerodynamic condition 
It was demonstrated using data from Tippman et al. [17] that impact time was approximately proportional to particle diameter for particles between 25.4 and $50.8 \mathrm{~mm}$, impinging at constant velocity. If this effect is replicated for the smaller particles used in this experiment, then this may explain the linear trend in Fig. 23.

Roisman et al. also developed a semi-empirical quantity to describe the likelihood of particle fragmentation, as a function of impact velocity resolved normal to the surface and initial diameter. This is given by Equation 16.

$$
\gamma=v_{\mathrm{n}_{0}} d_{\mathrm{p}_{0}}^{2 / 3}
$$

Fragmentation was assessed to be likely if $\gamma$ exceeded $\sim 0.04$ for a dry wall and $\sim 0.10$ for a wall with a water film. The nominal normal impact velocities for the MMD range is shown in Table 6 . The nominal Mach number was held at 0.4 for all tests. Using Equation 16, the corresponding values of $\gamma$ were calculated, as well as particle Stokes number.

The data shows that fragmentation is expected for all particles that impinge heavily on the plate ( $40 \mu \mathrm{m}$ and above). The impact dynamics for these tests is therefore likely to be similar, indicating that the increasing impact time could be a principle driver of the increasing heat transfer.

Table 6 - Values of Stokes number and $\gamma$ for the range of experimentally tested particle diameters. An orange cell denotes $\gamma>0.04$, and a blue cell Stk $>1$.

\begin{tabular}{lllll}
$M$ & $v_{n_{0}}(\mathrm{~m} / \mathrm{s})$ & $d_{p_{0}}(\mu \mathrm{m})$ & $\gamma\left(\mathrm{m}^{5 / 3} / \mathrm{s}\right)$ & $S t k$ \\
\hline 0.4 & 44.2 & 10 & 0.026 & 0.076 \\
\hline 0.4 & 44.2 & 20 & 0.032 & 0.30 \\
\hline 0.4 & 44.2 & 40 & 0.052 & 1.22 \\
\hline 0.4 & 44.2 & 60 & 0.068 & 2.74 \\
\hline 0.4 & 44.2 & 80 & 0.081 & 4.78
\end{tabular}

\section{(iii) Effect of Mach number}

Mach number was varied between 0.1 and 0.5 by varying freestream velocity at constant altitude and total temperature. Reynolds number is therefore also increasing in these tests. Stanton number enhancement at a constant TWC of $1.0 \mathrm{~g} / \mathrm{m}^{3}$ is shown in Fig. 24. The data shows that the enhancement factor of approximately 1.7 at Mach 0.4, also observed during other baseline condition runs, appears to be a plateau, within experimental uncertainty. The rise in heat transfer enhancement between Mach 0.1 and Mach 0.3 is attributable to the particle Stokes number increasing towards unity, resulting in gradually increasing particle impingement rate. Fig. 18 shows that at Mach 0.1 , less than $40 \%$ of the injected TWC is expected to impinge on the $66 \%$ streamwise row of gauges, where the data in Fig. 25 is taken.

The nominal MMD $(40 \mu \mathrm{m})$ and TWC $\left(1.0 \mathrm{~g} / \mathrm{m}^{3}\right)$ are constant, and so again any variation in heat transfer between cases is likely driven by impact dynamics. Values of $\gamma$ were again calculated, as shown in Table 7. For tests at Mach 0.1 and 0.2, $\gamma$ is below the threshold value of 0.04 ; it is approximately equal to it at Mach 0.3 and above it for Mach 0.4 and Mach 0.5. It is important to note that increasing impact velocity will decrease impact time for fragmenting particles, as the yield strength $\sigma_{y}$ is strain rate dependent. Tippmann et al. [17] studied the effect of impact velocity on yield strength, compared to a static case. Over the range of velocities studied here, yield strength may be expected to vary by approximately $30 \%$ [17], however when the square root is applied on the denominator of Equation 15, impact time may be considered approximately constant. Therefore, heat transfer enhancement was observed to be approximately constant for fragmenting ballistic particles at constant TWC and impact time. However, the data is not independent of Reynolds number. This is addressed in the following section.

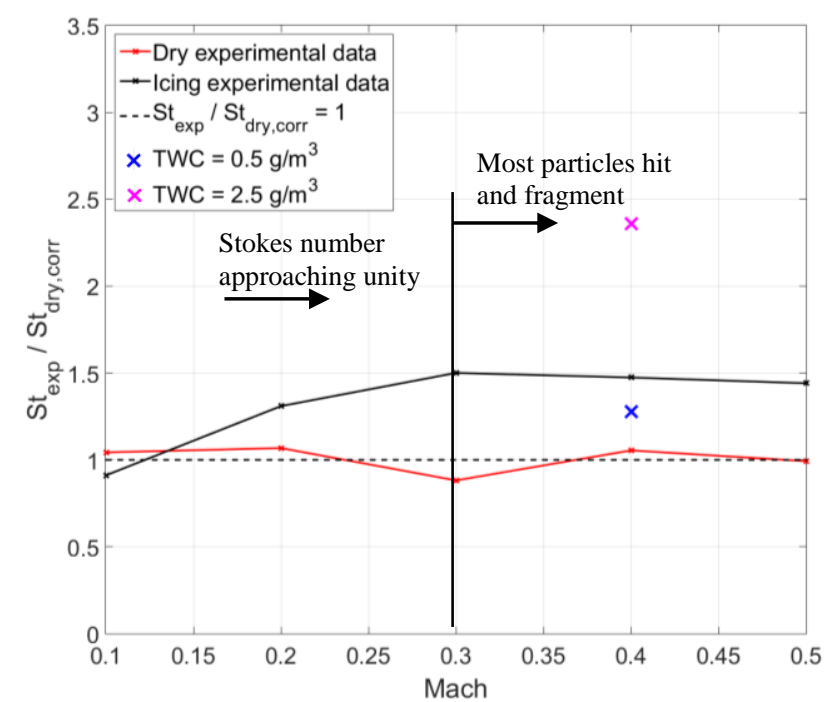

Fig. 24 - Stanton number enhancement against Mach number, $T W C=1.0 \mathrm{~g} / \mathrm{m}^{3}$

Table 7 - Values of Stokes number and $\gamma$ for the range of experimentally tested Mach numbers. An orange cell denotes $\gamma$ $>0.04$, and a blue cell Stk > 1 .

\begin{tabular}{lllll}
$M$ & $v_{n_{0}}(\mathrm{~m} / \mathrm{s})$ & $d_{p_{0}}(\mu \mathrm{m})$ & $\gamma\left(\mathrm{m}^{5 / 3} / \mathrm{s}\right)$ & $S t k$ \\
\hline 0.1 & 11.2 & 40 & 0.013 & 0.31 \\
\hline 0.2 & 22.4 & 40 & 0.026 & 0.61 \\
\hline 0.3 & 33.4 & 40 & 0.039 & 0.92 \\
\hline 0.4 & 44.2 & 40 & 0.052 & 1.22 \\
\hline 0.5 & 54.8 & 40 & 0.064 & 1.51
\end{tabular}

(iv) Effect of dynamic pressure

Runs were conducted at varying dynamic pressures in order to observe the effect of varying Reynolds number at constant Mach number. Dynamic pressure was varied between 5 and $13 \mathrm{kPa}$ (0.7-1.8 psi) by varying altitude at constant velocity and total temperature. Fig. 25 shows Stanton number enhancement for three tests, at dynamic pressures of 5015, 7376 and $12270 \mathrm{~Pa}$. The baseline test case of Mach 0.4 at an altitude of $5.5 \mathrm{~km}$ 
corresponds to the $5015 \mathrm{~Pa}$ case. The heat transfer in dry conditions is well matched to the correlation of Motwani et al., implying the effect on Reynolds number is well captured. In icing conditions, it is difficult to determine a trend in Stanton number enhancement, as it appears to be approximately constant within the uncertainty of the experiment.

Calculating the ratio of experimental Nusselt number to correlation Nusselt number $\left(\mathrm{Nu}_{\exp } / \mathrm{Nu}_{\text {dry,corr }}\right)$, the values are 1.54 and 1.58 for the lowest and highest dynamic pressures respectively, which in turn produces the approximately constant Stanton number enhancement shown in Fig. 25.

This can partially be attributed to Stokes number exceeding unity and $\gamma$ exceeding 0.04 for all three testpoints, hence ballistic fragmenting particles are expected for all cases. However it also implies an independency to Reynolds number, over the range tested. Given the heat transfer enhancement plateau in section (iii), where Reynolds and Mach number were both varied, the result of Reynolds number independency furthermore implies Mach number independency. It is important to note however that both of these conclusions are valid only for fully glaciated particles.

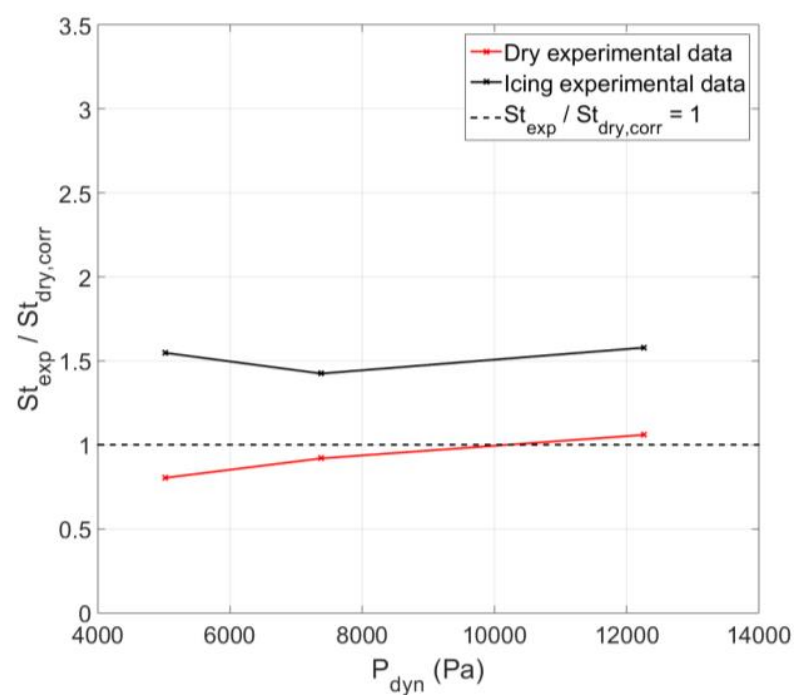

Fig. 25 - Stanton number enhancement against dynamic pressure. $T W C=1.0 \mathrm{~g} / \mathrm{m}^{3}$

\section{(v) Effect of angle of attack}

The angle of attack (AoA) of the flat plate was varied between $10^{\circ}$ and $30^{\circ}$, using the baseline aerodynamic and icing conditions given in Table 2. Stanton number enhancement is show in Fig. 26. The data shows a non-linear increase of heat transfer enhancement as angle increases. These tests can be viewed as varying $\gamma$ (as normal impact velocity increases with angle) at constant Stokes number. The analysis of Roisman et al. is performed once again, as shown in Table 8 . At $10^{\circ}$ angle of attack, fragmentation is unlikely. Additionally, smaller particles in the size distribution will follow the flowfield over the leading edge separation bubble and only impinge on the late heat transfer surface, if at all. At higher angles, fragmentation is likely and the effect of the separation bubble is eradicated.

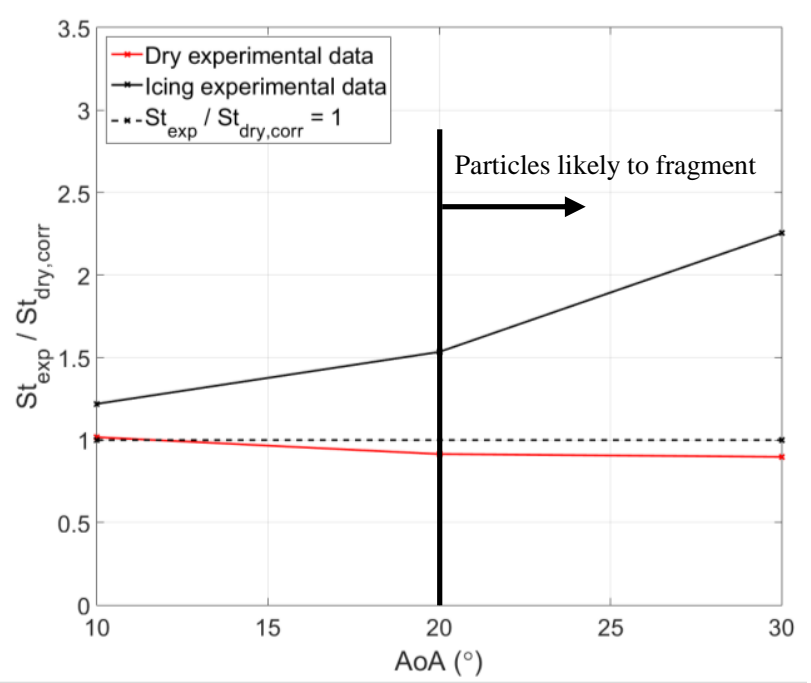

Fig. 26 - Stanton number enhancement against angle of attack. $T W C=1.0 \mathrm{~g} / \mathrm{m}^{3}$

Table 8 - Values of $\gamma$ for the range of experimentally tested angles of attack. An orange cell denotes $\gamma>0.04$.

\begin{tabular}{lllll}
$M$ & $\alpha\left(^{\circ}\right)$ & $v_{n_{0}}(\mathrm{~m} / \mathrm{s})$ & $d_{p_{0}}(\mu \mathrm{m})$ & $\gamma\left(\mathrm{m}^{5 / 3} / \mathrm{s}\right)$ \\
\hline 0.4 & 10 & 22.4 & 40 & 0.026 \\
\hline 0.4 & 20 & 44.2 & 40 & 0.052 \\
\hline 0.4 & 30 & 64.6 & 40 & 0.076
\end{tabular}

\section{CONCLUSIONS}

The development of a model for ice crystal accretion in gas turbine compressors requires, as one constituent part, an understanding of the thermodynamic and mechanical processes occurring when a bulk flow of ice particles impinges on a warm surface. A heated and instrumented flat plate was used to measure heat transfer enhancement over a range of aerodynamic and icing conditions. Thin film heat transfer gauges were successfully used for the first time in glaciated and mixed phase environments. Total Water Content, particle diameter, Mach number, angle of attack and dynamic pressure were systematically varied. The following conclusions may be drawn:

1. Over the range of $0.5-3.0 \mathrm{~g} / \mathrm{m}^{3} \mathrm{TWC}$, heat transfer enhancement was approximately linear, resulting in a theoretical particle melt ratio of $30-40 \%$ for a substrate temperature of $35{ }^{\circ} \mathrm{C}$. Evidence of splashing events was observed. In a real engine environment, the meltwater and subsequent evaporative cooling would result in favourable conditions for accretion.

2. At a baseline condition of $1.0 \mathrm{~g} / \mathrm{m}^{3} \mathrm{TWC}$, heat transfer from the test piece was observed to be approximately double compared with dry conditions. This rises to an enhancement of approximately three times at $3.0 \mathrm{~g} / \mathrm{m}^{3}$. Due to centrifuging effects within an engine, local TWCs could be over ten times this value [18]. 
3. Heat transfer enhancement was also observed to be approximately linear with particle diameter at constant TWC. This was tentatively attributed to the increasing particle impact time.

4. For fully glaciated particles, heat transfer enhancement was observed to be dependent on impact dynamics. This was observed in tests where particle diameter, Mach number and angle of attack were varied. A Stokes number of above unity resulted in high impingement rates and heat transfer enhancement. An empirical quantity $(\gamma)$ defined by Roisman et al. was used to predict the likelihood of fragmentation. At conditions where particles were both ballistic and likely to fragment, heat transfer enhancement was independent of Reynolds number and Mach number, within the uncertainty of the experiment.

5. When angle of attack was increased from 10 to $30^{\circ}$, heat transfer enhancement increased non-linearly in accordance with the rising normal impact velocity. In an engine environment, this has implications both for large particles with high tangential slip velocities, and also for variable geometry stages.

These conclusions will support development of a model for the ice crystal accretion phenomena, as well as providing simple predictive rules for use in preliminary engine design.

\section{ACKNOWLEDGEMENTS}

The authors would like to gratefully acknowledge the following people. Firstly, Rolls-Royce Plc and EPSRC for funding the project, and to Dr David Orchard, Catherine Clark, Gislain Chevrette and Stuart Stevenson at the NRC AIWT for their support and guidance throughout the experimental campaign. Also to Dr Khalid Saleh and Ramiz Ibraheem for providing insight and access to the ice crystal tunnel at the University of Southern Queensland, where the test article was developed. Also to Prof. Martin Oldfield and Dr Paul Beard of the Osney Thermofluids Laboratory for driving forward the development of the new TFG signal conditioning units, and to Trevor Godfrey, Gerald Walker, Brian Bunce, James Carter, Peter Forsyth and Sebastien Wylie for manufacturing the test article.

\section{REFERENCES}

[1] National Research Council Canada, 'Altitude icing wind tunnel', 22-Oct-2015. [Online]. Available:

http://www.nrc-

cnrc.gc.ca/eng/solutions/facilities/wind_tunnel/altitude_i cing.html. [Accessed: 11-May-2016].

[2] J. G. Mason, J. W. Strapp, and P. Chow, 'The Ice Particle Threat to Engines in Flight', 44th AIAA Aerospace Sciences Meeting and Exhibit, Reno, Nevada, 2006.

[3] J. G. Mason, P. Chow, and D. M. Fuleki, 'Understanding Ice Crystal Accretion and Shedding Phenomenon in Jet Engines Using a Rig Test', J. Eng. Gas Turbines Power, vol. 133, Apr. 2011.

[4] P. M. Struk, A.P. Broeren, J. Tsao, M. Vargas, W. B. Wright, T. Currie, D. Knezevici and D. Fuleki, 'Fundamental Ice Crystal Accretion Physics Studies', SAE
Tech. Int. Conf. Aircr. Engine Icing Ground Deicing Chicago, IL, USA. June 13-17 2011

[5] T. Currie, D. Fuleki, and A. Mahalllati, 'Experimental Studies of Mixed-Phase and Sticking Efficiency for Ice Crystal Accretion in Jet and Engines', 6th AIAA Atmospheric and Space Environments Conference, Atlanta, GA, 2014.

[6] T. C. Currie, D. M. Fuleki, D. C. Knezevici, and J. D. MacLeod, 'Altitude Scaling of Ice Crystal Accretion', 5th AIAA Atmospheric and Space Environments Conference, San Diego, California, U.S.A, 2013.

[7] I. Roisman, 'Ice particle collision with a dry rigid substrate and its breakup', SAE 2015 International Conference on Icing of Aircraft, Engines, and Structures, Prague, Czech Republic, 22-Jun-2015.

[8] O. M. Myron, F. H. Hyde, and P. J. Penna, 'In-flight Icing Simulation Capabilities of NRC's Altitude Icing Wind Tunnel', 39th AIAA Aerospace Sciences Meeting \& Exhibit, Reno, NV, U.S.A., 2001.

[9] National Research Council Canada, 'NRC Altitude Icing Wind Tunnel Calibration Reports, Appendix B. Report LTR-AL-2014-0118'. Jan-2015.

[10] M. Collins, K. Chana, and T. Povey, 'New technique for the fabrication of miniature thin film heat flux gauges', Meas. Sci. Technol., vol. 26, 2015.

[11] R. J. Anthony, M. L. G. Oldfield, T. V. Jones, and J. E. LaGraff, 'Development of high-density arrays of thin film heat transfer gauges', 5th ASME/JSME Thermal Engineering Joint Conference, San Diego, California, U.S.A, 1999.

[12] A. L. Lindsay and L. A. Bromley, 'Thermal Conductivity of Gas Mixtures', Ind. Eng. Chem., vol. 42, no. 8, pp. 1508-1511, Aug. 1950.

[13] D. G. Motwani, U. N. Gaitonde, and S. P. Sukhatme, 'Heat Transfer From Rectangular Plates Inclined at Different Angles of Attack and Yaw to an Air Stream', J. Heat Transf., vol. 107, pp. 307-312, May 1985.

[14] H. W. Coleman, W. G. Steele, 'Experimentation, Validation, and Uncertainty Analysis for Engineers' $3^{\text {rd }}$ Edition, 2009. Wiley. ISBN 978-0-470-16888-2

[15] Mitutoyo UK, 'Digimatic Protractor Pro 360', 2012. [Online]. Available: http://www.mitutoyo.co.uk/smalltool-instruments-and-data-management/protractors/950317.

[16] D. Fuleki, J. L. Chalmers, and B. Galeote, 'Technique for Ice Crystal Particle Size Measurements and Results for the National Research Council of Canada Altitude Ice Crystal Test System', SAE Tech. Pap. 2015-01-2125, 2015.

[17] J. D. Tippmann, H. Kim, and J. D. Rhymer, 'Experimentally validated strain rate dependent material model for spherical ice impact simulation', Int. J. Impact Eng., vol. 57, pp. 43-54, 2013.

[18] M. Feulner, S. Liao, B. Rose, and X. Liu, 'Ice Crystal Ingestion in a Turbofan Engine', SAE Tech. Pap. 2015-012146, 2015. 